Portland State University

PDXScholar

Summer 8-4-2015

\title{
Non-Steroidal Anti-Inflammatory Drug Use in Collegiate Athletes
}

Brian Robert Davis

Portland State University

Follow this and additional works at: https://pdxscholar.library.pdx.edu/open_access_etds

Part of the Other Public Health Commons, and the Sports Sciences Commons Let us know how access to this document benefits you.

\section{Recommended Citation}

Davis, Brian Robert, "Non-Steroidal Anti-Inflammatory Drug Use in Collegiate Athletes" (2015).

Dissertations and Theses. Paper 2477.

https://doi.org/10.15760/etd.2474

This Thesis is brought to you for free and open access. It has been accepted for inclusion in Dissertations and Theses by an authorized administrator of PDXScholar. Please contact us if we can make this document more accessible: pdxscholar@pdx.edu. 
Non-Steroidal Anti-Inflammatory Drug Use in Collegiate Athletes

by

Brian Robert Davis

A thesis submitted in partial fulfillment of the requirements for the degree of

\author{
Masters of Science \\ in \\ Health Studies
}

Thesis Committee:

Gary Brodowicz, Chair

James Wallis

Jonathan Huwe

Randy Logan

Portland State University 2015 


\begin{abstract}
Non-steroidal anti-inflammatory drugs (NSAID) are a class of medications used in the treatment of pain, inflammation, and illness. These medications are common, affordable, and easy to access. For these reasons, NSAIDs are commonly used by athletes of all backgrounds for treating injuries and as ergogenic aids. However, despite these behaviors, NSAIDs have well-documented side effects and the efficacious nature of these medications has been brought into question. Despite this, many athletes continue to use these medications frequently and indiscriminately. It is not known why athletes use these medications in light of their questionable effectiveness and cited adverse effects. Therefore, this study was designed to (1) further investigate the prevalence of NSAID use in collegiate-level athletes, (2) investigate attitudes and behaviors toward the use of NSAIDs cross-tabulated by sport, gender, and competition level, and (3) investigate athletes' general knowledge of NSAIDs.

Subjects for this study included 79 student-athletes (44 male; 25 female) attending Portland State University (PSU). The majority of the athletes started taking NSAIDs before high school ( $72 \%$ of the males and $64 \%$ of the females). Thirty-three percent of males and $32 \%$ of females reported that they had been taking NSAIDs within the past week. High in-season use of NSAIDs was reported by $52 \%$ of the male athletes and $48 \%$ of the female athletes, whereas off-season use was reported by $21 \%$ and $12 \%$ of the males and females, respectively. Cited reasons for NSAID use both in-season and off-season were relief of pain due to injury, prevention, recovery, soreness, and tightness. In total, $83 \%$ of males and $76 \%$ of females reported obtaining NSAIDs primarily through means
\end{abstract}


other than health-care professionals. With regard to dosage, athletes reported taking NSAIDs based on product directions, instructions of an athletic trainer or perceived pain levels. An overwhelming majority of athletes ( $83 \%$ male; $76 \%$ female) were not aware of any side-effects from taking NSAIDs

In summary, this study revealed a pattern of high NSAID use in athletes competing in-season compared to a high prevalence of low NSAID use in athletes offseason. It also revealed a high prevalence of non-prescription NSAID use. Additionally, there was a high prevalence of self-purchasing of NSAIDs, combined with selfmedication and a long history of NSAID use. This study also revealed a general lack of knowledge about NSAIDs. 


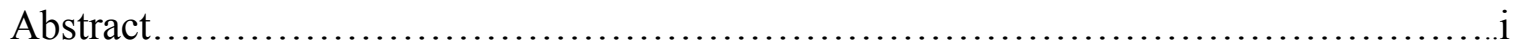

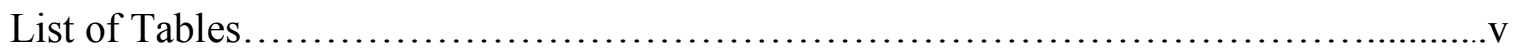

List of Figures.............................................................

Glossary.............................................................. vii

Chapter 1

Introduction..................................................................

Introduction.......................................................

Statement of Problem.......................................................

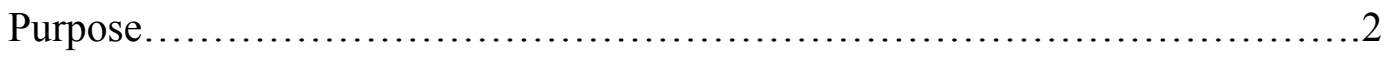

Chapter 2

Review of Literature...................................................... 4

General Information on NSAIDs.....................................4

NSAID Use in Athletic Populations....................................... 5

Reasons for Use in Athletes.......................................... 8

Efficacy of NSAIDs............................................... 10

Adverse Effects...................................................... 13

Guidelines for Use................................................. 19

Future Research/Recommendations.....................................21

Chapter 3

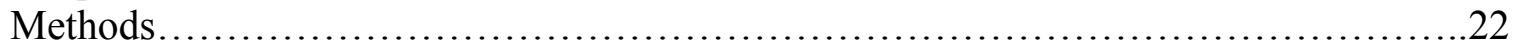

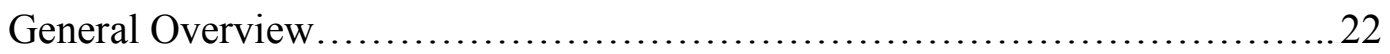

Subjects....................................................... 22 
Eligibility Criteria................................................. 23

Data Collection................................................................ 23

Variables.......................................................... 25

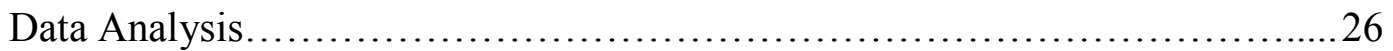

Chapter 4

Results................................................................... 27

Chapter 5

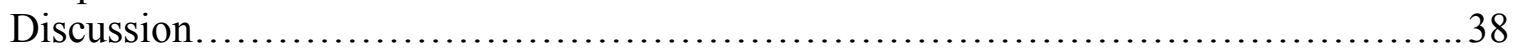

Limitations........................................................ 42

Conclusion.......................................................... 42

References.............................................................44

Appendices.............................................................60

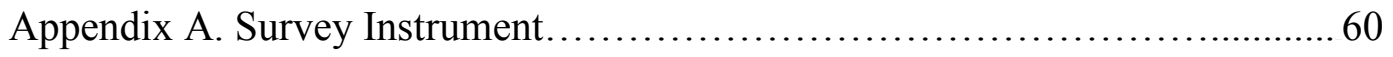

Appendix B. Consent Form............................................ 67

Appendix C. Human Subjects Approval....................................69

Appendix D. Table 2. Survey Response Data.................................71 
List of Tables

Table 1. Subject Descriptive Data.............................................. 27 
List of Figures

Figure 1. Summary of responses to question 2 ("When did you first use NSAIDs?")

Figure 2. Summary of responses to question 5 ("Are you currently taking any NSAIDs?") and question 6 ("Are you currently taking NSAIDs that were prescribed to you by a doctor or medical professional (Physical therapist, Athletic trainer, etc.)?

Figure 3. Summary of responses to question 8 ("How often do you use NSAIDs while competing IN-SEASON?"), and question 9 ("How often do you use NSAIDs while training in the OFF-SEASON?"). High = "Frequently" + "Regularly"; Low $=$ "Infrequently".

Figure 4. Summary of responses to question 10 ("What are your reasons for using NSAIDs while competing IN-SEASON?") and question 11 ("What are your reasons for using NSAIDs while training in the OFF-SEASON? ”)..............34

Figure 5. Summary of responses to question 12 ("From whom do you PRIMARILY

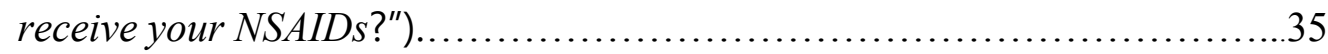

Figure 6. Summary of responses to question 13 ("How do you TYPICALLY determine the dose of NSAIDs to take at a given time?")...

Figure 7. Summary of responses to question 15 ("Have you heard of NSAIDs causing any side effects?") 


\section{Glossary}

Cyclooxygenase (COX): Enzyme responsible for the formation of prostaglandins.

Delayed Onset Muscle Soreness (DOMS): Pain and stiffness felt in muscles several hours to days after unaccustomed or strenuous exercise.

Inflammation: The body's initial response to harmful stimuli, which quarantines the area and initiates the healing process. Symptoms of inflammation include pain, redness, swelling, heat, and loss of function.

Non-Steroidal Anti-Inflammatory Drugs (NSAID): Medications that have analgesic (pain relieving), antipyretic (fever-reducing), antithrombotic (blood-thinning), and antiinflammatory properties. These drugs can either be prescribed or purchased over-thecounter (OTC).

Over-the-Counter (OTC): Medications that can be purchased and administered without a prescription.

Prophylactic: Guarding from or preventing the spread or occurrence of something.

Prostaglandins (PG): Fatty acid derivatives that are important in the regulation of inflammation 


\section{Chapter 1}

Introduction

\section{$\underline{\text { Introduction }}$}

Competitive athletes at all levels typically put in a great deal of time and effort to meet the physical demands of their sports. While athletes work to meet these demands, their bodies are at increased risk of injury. In 2002, 20.3 million sports-related injuries were estimated to have occurred in the U.S., or 70.5 injuries per 1000 persons (Warden, 2005). Because athletic endeavors are associated with a high amount of physical stress and injury, athletes rely on various methods to help minimize possible negative effects of training and competition.

One of the most popular methods used by athletes to assist with athletic-ailments is the use of non-prescription pain relievers, specifically, non-steroidal anti-inflammatory drugs (NSAID) (Lanier, 2004; Ziltener, Leal, \& Fournier, 2010). NSAIDs are a class of analgesic (pain relieving) medications used in the treatment of pain, inflammation, and illness. NSAIDs are well-known for being relatively cheap and easy to access as most of these medications can be purchased over-the-counter (OTC) at various general stores and pharmacies. NSAIDs are not only popular with athletes due to their affordability and ease of access, but also due to the social acceptability of their use, their ease of administration, and high amounts of observed use by peers (clinicians, parents, friends, siblings, etc.) (Holmes, Cronholm, Duffy, \& Webner, 2013; Warner, Schnepf, Barrett, Dian, \& Swigonski, 2002). Thus, NSAIDs are used at one's leisure without fear of repercussions or stigmatization (Holmes et al., 2013; Warner et al., 2002). It is for these 
reasons, NSAIDs are a popular drug of choice for athletes treating painful musculoskeletal injuries, chronic inflammatory conditions, and looking to increase athletic performance (Correa et al., 2012; Da Silva et al., 2011).

\section{Statement of Problem}

While NSAIDs are a staple medication for the treatment of sports injuries and inflammatory conditions, it is well-known that these medications can have serious sideeffects (Moore, 2007; Paoloni et al., 2010; Warden, 2010; Ziltener et al., 2010). Additionally, the efficacy of NSAIDs has been highly debated over the last couple of decades, thus putting into question whether these drugs work as they are intended to (Correa et al., 2012; Hasson et al., 1993; Yamamoto et al., 1999). It has also been reported that misuse and lack of knowledge in relation to NSAIDs is high amongst athletes (Corrigan \& Kazlauskas, 2003; Da Silva et al., 2011; Holmes et al., 2013; Warner et al., 2002). Furthermore, clinicians working with athletes vary on their educational understanding of NSAIDs, therefore, prescription and dispensing of these medications is inconsistent (Holmes et al., 2013; Lanier, 2004; Van Wijck et al., 2012). Because of these reasons and their commonality and acceptability in society, athletes worldwide continue to use these medications indiscriminately without proper supervision or education, thus putting them at a higher risk for experiencing adverse events.

Purpose

Currently, there is limited research on NSAID use within diverse athletic populations, such as colleges, universities, and secondary schools. While a handful of studies have shed light on the prevalence of NSAID use in athletic populations (Berglund 
\& Sundot-Borgen, 2001; Da Silva et al., 2011; Holmes et al., 2013; Warner et al., 2002) few studies have investigated knowledge, behaviors, and attitudes (Warner et al., 2002) associated with NSAID use. It can be hypothesized that athletes would likely limit their use of NSAIDs if they were educated about the proper use and potential side-effects associated with these medications, however, more research is needed on a diverse range of athletes to test this hypothesis. Therefore, it is the duty of health-care professionals and researchers alike to investigate how NSAID use differs between competition level, sport, gender, age, and social background. Doing so can help provide insight as to why athletes continue to indiscriminately use NSAIDs despite their well-noted side-effects and questionable effectiveness. Having this information can help facilitate the implementation of policies and programs that can educate athletes about the proper use of these medications, increase regulations around ease of access, and further advance the field of sports medicine.

For these reasons this study was designed to (1) further investigate the prevalence of NSAID use in a collegiate-level athletes, (2) investigate attitudes and behaviors toward the use of NSAIDs cross-tabulated by sport, gender, and competition level, and (3) investigate athletes' general knowledge of NSAIDs. 
Chapter 2

Review of Literature

This literature review was conducted using the Portland State University Library

online database system. Research literature was found using science and health databases such as Health Source, MEDLINE, EBSCO, PubMed, SPORTDiscus, and Web of Science. The keywords NSAIDs, athletes, non-steroidal anti-inflammatory drugs, analgesics, pain relieving drugs, sports and pain medication, over-the-counter pain medication, and performance enhancing drugs were used to help locate relevant published research.

\section{General Information on NSAIDs}

Early studies show that $30 \%$ of adults have used one or more nonprescription medications in the previous 48 hours (Bush \& Rabin, 1976), while more than 50\% of children have taken non-prescription medications within the same time frame (Kohn \& White, 1976). A more recent study found up to $75 \%$ of adolescents use non-prescription medications without consulting an adult (Chambers, Reid, McGrath, \& Finley, 1997). Of these non-prescription medications, analgesics such as non-steroidal anti-inflammatory drugs (NSAID) are the most commonly used (Warner et al., 2002).

NSAIDs are a class of medications used in the treatment of acute and chronic pain. They are among the most commonly used medications with a worldwide market of over $\$ 6$ billion each year (Wallace, 1997). Most NSAIDs are categorized as cyclooxygenase (COX) inhibitors and thus exert their effects through acting on one of two main COX isozymes named COX-1 and COX-2 (Warden, 2005). Commonly referred to as the "housekeeping" isoform, $\mathrm{COX}-1$ garners this title due to its structural 
features and its predominantly constitutive expression (Vane \& Botting, 1998). COX-2, on the other hand, is referred to as the inducible isoform because it is brought about in response to a variety of stimuli (Vane \& Botting, 1998). NSAIDs that inhibit the COX-1 isozyme represent the bulk of the market and are the only type of NSAIDs that can be purchased "over-the-counter", whereas NSAIDs that inhibit the COX-2 isozyme are typically only obtained via prescription from a medical professional.

The therapeutic effects of NSAIDs are made possible through the prevention of prostaglandin (PG) synthesis via the inhibition of the COX enzyme (Vane, 1971). Most NSAIDs accomplish this by reversibly inhibiting COX by competing with the substrate arachidonic acid for the active site of the enzyme, thereby preventing the conversion of arachidonic acid to PG (Vane, 1971; Vane \& Botting, 1998). Other NSAIDs—such as aspirin—act differently; they inhibit prostaglandin synthesis through the irreversible acetylation of COX (Lieber \& Friden, 2002).

\section{NSAID Use in Athletic Populations}

There were an estimated 20.3 million sports-related injuries in the US during the year 2002, which is approximately 70.5 injuries per 1000 persons (Warden, 2005). There are only a handful of published studies on the prevalence of NSAID use in athletes, but a growing awareness of the extent of NSAID consumption in the sporting world has begun to emerge in the last decade. Reports document a high prevalence of NSAID use across a variety of athletes, ranging from youth sports to elite Olympic athletes (Alaranta, Alaranta, \& Helenius, 2008; Holmes et al., 2013; Tscholl, Junge, \& Dvorak, 2008; Tscholl, Alonso, Dolle, Junge, \& Dvorak, 2010; Warner et al., 2002). Survey studies 
investigating NSAID use in high-level international athletes have found this class of medication to be the most frequently used (Corrigan \& Kazlauskas, 2003; Huang, Johnson, \& Pipe, 2006; Taioli, 2007; Tscholl et al., 2008). While daily NSAID use in the general population is reported to be around 1-4\% (Barozzi \& Tett, 2008; Leufkens, Ameling, Hekster, \& Bakker, 1990), the reported daily use of NSAIDs by elite Olympic athletes and international soccer players is as high as $25-35 \%$ (Corrigan \& Kazlauskas, 2003; Huang et al., 2006; Tscholl et al., 2008). Data from other studies indicate a wide range of NSAID use in different sports, ranging from $12 \%$ in cyclists to more than $90 \%$ in professional soccer players (Gorski et al., 2011; Taioli, 2007; Thuyne \& Delbeke, 2008). Reports have also found concomitant use of up to five different anti-inflammatory agents in approximately $10 \%$ of high-level athletes (Corrigan \& Kazlauskas, 2003; Tscholl et al., 2008).

In a study of 1261 international athletes at the 2007 Pan-American Games, Da Silva et al. (2011) found that $63 \%(\mathrm{n}=792)$ of the athletes were using NSAIDs. Of those athletes that were currently competing in their sport $(n=1030), 65 \%(n=670)$ were using NSAIDs. Of those athletes that were not competing in their sport $(\mathrm{n}=231), 56 \%$ $(\mathrm{n}=129)$ were using NSAIDs. This study confirmed previous observations of high NSAID use in athletes while in-competition, but also demonstrated high use while out of competition. Furthermore, this study observed that higher use of NSAIDs while incompetition than out of competition suggests that some athletes may use these medications as ergogenic aids. 
Berglund and Sundot-Borgen (2001) interviewed approximately 500 Swedish Olympic athletes participating from 1996-2000. In their study they found NSAID use was approximately six- to ten-fold higher than in the general population of the same age. Huang et al. (2006) studied approximately 500 Olympic athletes from the 1996 and 2000 Olympic Games where NSAID use was reported as high as $38 \%$, with the highest usage patterns exhibited by softball (60\% of participants) and gymnastics (100\% of participants). Corrigan and Kazlauskas (2003) found that $26 \%$ of athletes at the 2000 Sydney Olympics reported NSAID use within the previous three days. It was also noted that inappropriately high doses and concomitant use of several different NSAIDs were common amongst those athletes.

Holmes et al. (2013) conducted a recent study in which they surveyed 211 NCAA Division I and Division III football athletes on the prevalence of NSAID use in a collegiate football setting. Of the athletes surveyed, $96 \%$ had used NSAIDs at some time. Players reported initial use of NSAIDs as early as junior high (46\%) and high school (49\%), whereas only 5\% started taking NSAIDs in college. Athletes also reported receiving NSAIDs from a variety of sources during the year: self (81.0\%), parents (54.5\%), trainers (29.9\%), physicians (27.0\%), teammates (5.7\%), and coaches $(1.4 \%)$. They also found that $50.0 \%$ of participants reported high NSAID use during the season, compared to $14.6 \%$ during the off-season. This means athletes were significantly more likely to use NSAIDs during the in-season if they reported off-season use. The study further examined NSAID use before, during, and after practices and games. Responses were dichotomized into low (never and sometimes) and high usage (usually and always) 
categories. Before games, $10.9 \%$ of the athletes reported high use of NSAIDs, while only $0.5 \%$ reported high use during games, and $32.7 \%$ reported high use after games. This study demonstrated high prevalence of NSAID use among collegiate football players and also demonstrated high rates of self-medication and parental sourcing of NSAIDs, presumably without knowledge of the medical team (i.e., athletic trainers and physicians).

Joslin, Lloyd, Kotlyar, and Wojcik (2013) investigated NSAID usage patterns between ultra-distance (UD) marathon runners and regular-distance (RD) marathon runners. They looked at usage patterns during training, during competition, and during recovery. Out of 73 athletes that were surveyed (27 UD and 46 RD), $70 \%$ of UD runners used NSAIDs during competition, while 59\% used during training, and 59\% used during recovery. The NSAID usage pattern for RD runners was $26 \%$ during competition, $63 \%$ during training, and $61 \%$ during recovery. There was a high prevalence of NSAID use in both types of runners, especially during training.

\section{$\underline{\text { Reasons for Use in Athletes }}$}

Due to the high physical demands, intensity, contact, and repetitive movements of competitive sports, there is a high frequency of physical trauma (Da Silva, 2011). It is for these reasons - accompanied by their anti-inflammatory and analgesic properties and their universal availability — that NSAIDs have seen widespread use among athletes of all ages (Lanier, 2004; Ziltener et al., 2010). It is also thought the negative association between pain and the ability to perform in athletic competition may mean athletes use NSAIDs to improve performance (Correa et al., 2012; Da Silva et al., 2011). Another 
possible reason for the use of NSAIDs by athletes is an attempt to minimize the degree of pain and inflammation that occurs from the repetitive practice of sport (Da Silva et al., 2011). It is generally believed that the inflammatory process and the accumulation of muscle edema following unaccustomed exercise contributes to the development of delayed onset muscle soreness (DOMS). As a result, both prophylactic and therapeutic use of NSAIDs for the treatment of DOMS has been observed in athletes (Alaranta et al., 2008; Lanier, 2004; Tscholl et al., 2010; Warden, 2009; Warden, 2010; Warner et al., 2002; Ziltener et al., 2010).

Warner et al. (2002) performed a study in which they surveyed NSAID use in high school football players. A total of 604 players returned completed surveys; 452 players $(75 \%)$ reported using NSAIDs in the previous months for reasons related to their sport, while 90 players (15\%) described daily use of NSAIDs. Daily NSAID users were more likely to feel an advantage in taking NSAIDs than a disadvantage, in order to block pain before it occurred, to administer NSAIDs without supervision, and to decide the dosage without supervision. Players who perceived that their performance was enhanced by using NSAIDs, who decided on their own when to administer NSAIDs, and/or used NSAIDs to stop pain prophylactically rather than after the onset of pain were significantly more likely to use NSAIDs daily.

This study demonstrated that up to one in seven high school football players misuse NSAIDs, meaning the use of NSAIDs among high school football players is high, and the recognition of associated risks is low. This study also found that daily users are more likely to decide on their own when to use NSAIDs, and to use prophylactically, thus 
leading to the likelihood that supervising adults are unlikely to be aware of NSAID misuse.

\section{Efficacy of NSAIDs}

NSAIDs have known anti-inflammatory, analgesic, antipyretic and antithrombotic effects (Paoloni, Milne, Orchard, \& Hamilton, 2010). They have also been shown to be modestly effective in the treatment of pain when compared to a placebo (Almekinders, 1999). Additionally, study reviews looking at the effects of NSAIDs on various maladies have found NSAIDs to be effective in treating chronic inflammatory conditions such as rheumatoid arthritis (Paoloni et al., 2010; Warden, 2005). While using NSAIDs for pain and chronic inflammatory conditions may be indicated, the effectiveness of NSAIDs outside of these reasons is uncertain.

As mentioned earlier, prophylactic NSAID use is popular amongst athletes trying to mitigate the effects of DOMS. While using NSAIDs to treat DOMS may seem logical due to their anti-inflammatory and analgesic properties, the efficacy of NSAID therapy for the treatment of DOMS in sport is controversial and challenging to review. NSAID use could contribute to reduced pain as a result of reduced muscle edema; however, investigations examining this theory are inconsistent, with roughly equal numbers finding no effect of NSAIDs on DOMS (Donnelly, McCormick, Maughan, Whiting, \& Clarkson, 1988; Donnelly, Maughan, \& Whiting, 1990; Grossman, Arnold, Perrin, \& Kahler, 1995; Howell, Conaster, Chleboun, Karapondo, \& Chila, 1998a; Howell, Conaster, Chleboun, Karapando, \& Chila, 1998b; Kuipers, Keizer, Verstappen, \& Costill, 1985; Peterson et al., 2003; Pizza, Cavender, Stockard, Baylies, \& Beighle, 1999; Semark, Noakes, St. 
Clair Gibson, \& Lambert, 1999; Stone, Merrick, Ingersoll, \& Edwards, 2002), or a significant attenuation of DOMS (Baldwin, Stevenson, \& Dudley, 2001; Dudley et al., 1997; Francis \& Hoobler, 1987; Hasson et al., 1993; Lapointe, Fremont, \& Cote, 2002; Lecomte, Lacroix, \& Montgomery, 1998; Mishra, Friden, Schmitz, \& Lieber, 1995; O’Grady et al., 2000; Sayers, Knight, Clarkson, Van Wegen, \& Kamen, 2000; Tokmakidis, Kokkinidis, Smilios, \& Douda, 2003; Trappe, Fluckey, White, Lambert, \& Evans, 2001).

Hasson et al. (1993), investigated the influence of acute doses of ibuprofen in conjunction with strength training and found decreases in DOMS, but no difference in creatine kinase (CK) levels. Correa et al. (2012) conducted a recent study examining the effects of NSAIDs used before resistance exercise. In their study they did not find a significant difference between the use of ibuprofen or placebo in total strength training volume or creatine kinase (CK) levels before or after exercise. This suggests that NSAIDs may reduce soreness due to their analgesic effect, but they do not influence muscle damage. In light of the controversy surrounding NSAIDs and their effectiveness in treating DOMS, the potential for adverse effects and the possibility of a negative effect on recovery may override the use of NSAIDs as modality in the treatment of DOMS (Barnett, 2006; Peterson et al., 2003).

Other studies have investigated the efficacy of NSAID use for strength training. Krentz, Quest, Farthing, Quest, and Chilibeck (2008) investigated the effects of ibuprofen on non-trained males during a six-week strength training program; their results yielded no evidence of a hypertrophic effect on the subjects. Trappe et al. (2011) found that 
ibuprofen administration enhanced muscle strength and muscle size during a strength training regimen in older adults. While these findings require further investigation, it can be inferred that NSAID treatment may have a positive effect on muscle injury/recovery in individuals with elevated levels of inflammatory cytokines, as is the case for many older adults (Mackey, Mikkelsen, Magnusson, \& Kjaer, 2012).

NSAIDs are commonly used in conjunction with acute and reoccurring muscular injury, however, whether NSAIDs are beneficial or detrimental to muscular injury remains unclear (Lanier, 2004; Mackey et al., 2012; Paoloni et al., 2010). Reynolds, Noakes, Schwellnus, Windt, and Bowerbank (1995) conducted a randomized, doubleblind, placebo-controlled trial on the effects of NSAIDs on acute hamstring injuries. Both the placebo group and the treatment group received the same physical therapy routine. Results indicated that reduction of pain and swelling and return to normal strength were no better with or without NSAIDs. In fact, reduction of pain was better in the placebo group. Rahusen, Weinhold, \& Almekinders (2004) conducted a study comparing the analgesic effects of NSAIDs vs non-anti-inflammatory analgesics in adult mice. The results of the study indicated that NSAIDs were no more effective in treating a muscle contusion than an analgesic without anti-inflammatory effects, such as acetaminophen. Despite the fact that NSAIDs may be effective at decreasing inflammation and therefore decreasing pain, analgesics without anti-inflammatory properties may be just as effective in treating pain related to muscular injury (Rahusen et al., 2004). 
Human studies examining the effects of NSAIDs on ligament injuries have demonstrated that NSAIDs are effective at decreasing pain and allowing for a faster return to activity from acute ankle sprains (Ekman, Fiechtner, Levy, \& Fort, 2002; Mazieres, Rouanet, Velicy, Scarsi, \& Reiner, 2005; Moran, 1991; Slayter, Hensley, \& Lopert, 2003). Buvanendran et al. (2003) found that patients treated with COX-2 inhibitors following knee replacement surgery had lower in-hospital narcotic medication consumption, lower pain scores, greater knee range of motion, and shorter time in physical therapy than placebo-treated patients. While these studies demonstrate that NSAIDs can alleviate pain and facilitate a quicker return to normal function with ligament injuries, they do not determine whether or not there are long-term effects on tissue-level healing. Furthermore, they do not determine whether the use of NSAIDs results in ongoing morbidity and/or enhanced injury susceptibility (Warden, 2005).

There are some theories that suggest NSAIDs are incapable of affecting the peripheral inflammatory response. After soft tissue injury, PGs may be produced rapidly, before NSAIDs are available to inhibit the COX-PG pathway (Yamamoto et al., 1999). Also, other inflammatory mediators, such as kinins and histamine, may be present and allow an inflammatory response to progress without the presence of PGs (Rahusen et al., 2004).

\section{$\underline{\text { Adverse Effects }}$}

Reviews investigating the various effects of NSAID use in sport have found several adverse effects such as decreased prostaglandin synthesis in the gastrointestinal (GI) tract, changes in renal function, peripheral edema, hypertension, and inhibition of 
renal excretion of water and sodium and hyperkalemia (Alaranta et al., 2008; Moore, 2007; Paoloni et al., 2010; Warden, 2010; Ziltener et al., 2010). These effects may contraindicate the administration of NSAIDs as an ergogenic agent in such activities as aerobic and anaerobic training (Correa et al., 2012). Additionally, many believe that the analgesic effect of NSAIDs can mask the pain of an injury and thus prevent the athlete from resting long enough to allow for proper healing (Baker, Cotter, Gerrard, Bell, \& Walker, 2005; Warden, 2009).

NSAIDs are anti-inflammatory agents, meaning they are responsible for decreasing inflammation. In certain circumstances, a decrease in inflammation may be a desired effect; however, the inflammatory response is a way for the body to clear away injured cells and tissue, thus initiating a healing response. Therefore, a marked decrease in the inflammatory response due to the use of NSAIDs may be a detriment to the healing process and ultimately result in poorer tissue regeneration (Gilroy et al., 1999; Jarvinen, Lehto, \& Sorvari, 1992; Mackey et al., 2012; Rankin, 2004; Warden, 2005; Warden, 2009).

Almekinders and Gilbert (1986) demonstrated via histological examination that muscle strains in adult rats treated with NSAIDs continue to weaken in the early postacute injury period. Elder, Dahners, and Weinhold (2001) investigated the effects of COX-2 inhibitors on tissue-level healing in rat ligaments. Ligament injuries treated with COX-2 inhibitors resisted $32 \%$ less force, absorbed $41 \%$ less energy, and were $21 \%$ more lax than ligaments in control animals with the same injuries. One study investigating the repair of tendinous injuries in rats found that COX-2 inhibitor injections given during the 
first five days following initial injury resulted in a $27 \%$ reduction in ultimate force and $25 \%$ reduction in ultimate failure stress compared to rats not treated with NSAIDs (Virchenko, Skoglund, \& Aspenberg, 2004). While studying the effects of NSAIDs on the recovery of contractile function following damage-causing exercise, Lapointe et al. (2002) found that rats treated with NSAIDs experienced a significantly greater deficit in muscular tetanic tension compared to placebo-treated rats. Studies on bone injuries in mice have found that COX-2 inhibition is responsible for significantly reduced ossification during fracture repair when compared to controls (Brown, Saunders, Kirsch, Donahue, \& Reid, 2004; Simon, Manigrasso, \& O’Connor, 2002; Zhang et al., 2002;) and decreased fracture site mechanical strength return (Endo et al., 2002; Gerstenfeld et al., 2003; Simon et al., 2002).

Explanations for the negative outcomes in studies investigating the healing processes of bones, muscles, tendons, and ligaments require careful consideration of the mechanism of action of NSAIDS. NSAIDs inhibit the binding of COX, which reduces the amount of inflammation-causing PGs produced (Warden, 2005). PGs have been shown to stimulate skeletal muscle protein synthesis, thus COX activity may be necessary for full skeletal muscle adaptation to overload (Warden, 2005). Because of this, NSAID use may inhibit the normal hypertrophic response to resistance training (Trappe et al., 2002). PGs also play an important role in bone homeostasis (Vuolteenaho, Moilanen, \& Moilanen, 2007); therefore altering PG synthesis can have an impact on proper bone healing (Ziltener et al., 2010). 
Several studies have shown positive effects when NSAIDs were used in addition to standard rehabilitation techniques in the treatment of ligament injuries; however, it is believed that while the decreased pain from NSAID use may allow an earlier return to training, the athletes ultimately have decreased stability and a decreased range of motion at the site of injury (Slayter et al., 1997). This leads to the question of whether NSAID use could also suppress the adaptive response of skeletal muscle connective tissue to exercise (Mackey et al., 2012). While the data from human studies exploring the potential of NSAIDs to limit muscle adaptation to resistance training is not clear (Trappe et al., 2011), NSAID ingestion has been reported to suppress the protein synthesis response in young individuals after a single bout of exercise (Trappe et al., 2002). Furthermore, one animal study investigating the effects of NSAIDs on resistance training found a $50-75 \%$ blunting of muscle hypertrophy in animals treated with NSAIDs (Soltow et al., 2006).

Recent studies have focused on satellite cells and their interaction with NSAIDs. Satellite cells are considered muscle "stem cells" because they have the capacity to repair damaged tissue and replenish their own cell pool (Mackey, 2013). Satellite cells are also very important for skeletal muscle adaption to exercise, they provide new myonuclei and repair damaged myofibers, which is crucial for successful regeneration following injury or exercise-induced muscle damage (Hawke \& Garry, 2001; Schultz \& McCormick, 1994). Studies have shown that COX enzymes are necessary for satellite cell activity (Mendias, Tatsumi, \& Allen, 2004) and muscle regeneration (Almekinders \& Gilbert, 1986), inhibition of COX through the use of NSAIDs suppresses these functions and 
decreases the mixed muscle protein synthesis rates normally observed following exercise (Trappe et al., 2002). Mackey et al. (2007) studied satellite cell activity during exercise and post-exercise via muscle biopsy. Their results suggest that ingestion of NSAIDs decreases satellite cell activity and therefore myogenesis and regeneration. Given the important role satellite cells have in skeletal muscle maintenance and regeneration, any substances that alter satellite cell activity (like NSAIDs) could inhibit the anabolic effects exerted by exercise (Mackey et al., 2007; Mackey, 2013).

Gastro-intestinal (GI) complications have been shown to occur within one to three months of chronic NSAID use (Gabriel, Jaakkimainen, \& Bombardier, 1991). Risk factors related to GI bleeding and NSAID use are bleeding abnormalities, age, history of ulceration, smoking, alcoholism, chronic NSAID use, simultaneous NSAID use, and consumption of large doses of NSAIDs (Lanier, 2004). Consumption of large doses of NSAIDs may be a greater risk factor to larger athletes as larger doses (1500-1800 $\mathrm{mg}$ /day) are required to produce anti-inflammatory effects (Lanier, 2004). Van Wijck et al. (2012) found that gastroduodenal and small intestinal permeability increased after cycling in subjects that were given ibuprofen prior to exercise. This study also found a clear relation between exercise-induced intestinal injury and small intestinal permeability after exercise. It demonstrated that the use of ibuprofen before exhaustive exercise exacerbates exercise-induced small intestinal injury and initiates gut barrier dysfunction in healthy endurance athletes.

Why NSAID consumption leads to GI damage and increased risk of upper GI complications has yet to be fully understood (Van Wijck et al., 2012). It is believed that 
COX is important in GI function, and therefore the inhibition of COX results in local inflammation and vascular dysregulation, therefore reducing gastric perfusion and compromising mucosal integrity within the splanchnic area (Crofford, 1997; Rodriguez \& Tolosa 2007). In addition, mucosal blood flow may by reduced due to the interference of NSAIDs with PGs (Martin, Jimenez, \& Motilva, 2001), this NSAID-induced reduction of blood flow may deteriorate splanchnic hypoperfusion, putting athletes at risk for serious GI complications (Van Wijck et al., 2012).

The National Kidney Foundation estimates that $10 \%$ of kidney failure is caused by overuse of NSAIDs (Joslin et al., 2013). Diminished renal function occurs with chronic use of NSAIDs however, acute renal failure can occur within 30 days of continuous use (Huerta, Castellsague, Varas-Lorenzo, \& Rodriguez, 2005). Also, renal damage has been reported in athletes taking NSAIDs during exercise (Walker, Fawcett, Flannery, \& Gerrard, 1994); this damage can be life-threatening in excessive heat (Griffiths, 1992). NSAIDs can have other adverse renal effects such as acute interstitial nephritis, nephrotic syndrome, membranous nephropathy, and chronic kidney disease (Huerta et al., 2005). Additionally, renal blood flow may be reduced up to $75 \%$ of normal levels during exercise; increased renal permeability during exercise along with dehydration leads to this phenomena (Baker et al., 2005). Furthermore, the increase in glomerular pressure and sodium retention caused by NSAIDs in combination with decreased blood flow due to exercise may further increase the effects of NSAIDs on athletes' renal function (Baker et al., 2005). 
Two major risks have been identified with using NSAIDs during endurance events: development of renal complications and exercise-associated hyponatremia (EAH) (Joslin et al., 2013). NSAIDs reduce PG synthesis in the kidney, causing a decrease in the rate of glomerular filtration and afferent renal blood flow (Baker et al., 2005; Warden, 2010). This combination of symptoms can impair an athlete's free water clearance, which increases the risk of developing renal disease and/ or EAH (Baker et al., 2005; Page, Reid, Speedy, Mulligan, \& Thompson, 2007). Furthermore, recent cases of renal failure in high profile basketball players has brought into question whether NSAIDs accelerate the onset of kidney disease (Holmes et al., 2013).

Recent studies and reviews of the effects of NSAIDs on the cardiovascular system have found links between certain COX inhibitors and increases in cardiac mortality and morbidity (Baron et al., 2008; Bavry et al., 2011; Couzin, 2004; Fitzgerald, 2004; Frantz, 2004; Graham et al., 2005; Mamdani et al., 2004; Trelle et al., 2011; Warden, 2005). Other recent evidence suggests that NSAIDs may significantly increase the risk of congestive heart failure in people with prior history of heart disease (Page \& Henry, 2000), which occurs due to an increase in vascular resistance due to interference with other medications such as aspirin and ACE inhibitors used to treat heart conditions (Lanier, 2004).

\section{Guidelines for Use}

It is important to recognize that the prevalence of NSAID use in athletes has been too high and has resulted in many adverse events. However, NSAID use should not be shunned completely because it is potentially helpful in many common sports medicine 
scenarios (Paoloni et al., 2010). The prescribing of NSAIDs should be cautious with careful consideration to both dose and duration and combined with other therapeutic modalities such as ice and rehabilitation (Joslin et al., 2013; Paoloni et al., 2010; Warden, 2009; Ziltener et al., 2010). It is recommended that NSAIDs be used in an approach where simple pain relief is the goal of treatment (Paoloni et al., 2010). Additionally, due to the fact that NSAIDs inhibit the inflammatory process and therefore may be detrimental to long-term healing, it is recommended that NSAID use be restricted to the acute or sub-acute phases (up to 1 week) of injury repair (Lapointe, Fremont, \& Cote, 2003; Warden, 2009).

Using NSAIDs during the sub-acute phase of injury, may have beneficial effects (Brickson et al., 2003) by limiting edema, myotube and capillary regeneration (Thorsson, Rantanen, Hurme, \& Kalimo, 1998), and maintaining tensile and contractile strength (Obremsky, Seaber, Ribbeck, \& Garrett, 1994). However, NSAID use may cause decreased tissue regeneration and increased fibrosis in the latter stages of healing and is therefore contraindicated (Thorsson et al., 1998).

Reports on the use of topical NSAIDs have begun to show promise as a safer alternative to orally administered NSAIDs. Topical NSAIDs deliver medication subcutaneously to a localized site of injury making them effective at treating minor injuries (Galer, Rowbotham, Perander, Devers, \& Friedman, 2000; Singh \& Roberts, 1994). Moore, Tramer, Carroll, Wiffen, and McQuay (1998) conducted a systematic review of randomized controlled trials (RCTs) and concluded that topical NSAID use was effective at relieving pain without serious adverse reactions. Akermark and 
Forsskahl (1990) performed a placebo-controlled, double-blind trial on the effects of topically and systemically administered NSAIDs. Their results favored the use of topical NSAIDs in superficial overuse injuries in athletes.

It has also been reported that using acetaminophen for pain reduction may be a better alternative to NSAIDs, due to its milder effect on the GI tract, kidneys, and tissue regeneration (Rahusen et al., 2004). Reports suggest that acetaminophen's pain-relieving capabilities may be comparable to those of NSAIDs (Rahusen et al., 2004).

\section{Future Research/Recommendations}

It is important to increase the awareness and education of medical professionals and athletes about the potential adverse effects of NSAIDs and to recommend that these medications be used in the presence of a clearly indicated medical condition (Alaranta et al., 2008; Holmes et al., 2013; Lanier, 2004; Van Wijck et al., 2012). Specifically, athletes require education that NSAIDs are principally indicated as short-term adjuncts for the alleviation of acute pain and inflammation during rehabilitation and injury. This means NSAIDs should not be used prophylactically (in the absence of injury) and that they do not represent a "cure-all" or a substitute to physical therapy (Warden, 2009). Finally, Holmes et al. (2013) states a need for longitudinal studies in more generalizable athlete populations in order to determine the true risks associated with NSAIDs and athletics. 


\section{Chapter 3}

\section{Methods}

\section{General Overview}

This study was intended to investigate prevalence of use, behaviors, and attitudes associated with NSAIDs in a sample of collegiate athletes. The subjects used for this study were student-athletes attending Portland State University (PSU). PSU is an NCAA Division I institution that sponsors approximately 300 NCAA Division I student athletes participating in 13 different sports. The specific sports teams at PSU are men's football, basketball, tennis, cross-country, and track, and women's basketball, softball, tennis, cross-country, track, golf, soccer, and volleyball.

Data were collected with a questionnaire developed to gather information about NSAID use among the student-athletes. Surveys asked participants to provide demographic information and information about their NSAID-related behaviors. Study participants were volunteers who met specific eligibility criteria (see Eligibility Requirements below). Data collection took place throughout a 4-week period. Data were collected by hand and input into a spreadsheet for descriptive analysis.

\section{$\underline{\text { Subjects }}$}

This study investigated the student-athlete population of PSU, which was comprised of 291 NCAA Division I student-athletes during the time of this study. PSU has 13 NCAA men's and women's collegiate sports, which include men's football (n= 97), men's basketball $(\mathrm{n}=17)$, men's tennis $(\mathrm{n}=8)$, men's cross-country $(\mathrm{n}=12)$, and men's track $(n=26)$, women's basketball $(n=14)$, women's softball $(n=19)$, women's 
tennis $(n=9)$, women's cross-country $(n=11)$, women's track $(n=31)$, women's golf $(n$ $=6)$, women's soccer $(n=30)$, and women's volleyball $(n=11)$.

\section{Eligibility Criteria}

In order to participate in this study, athletes had to be: (1) currently enrolled students at PSU, (2) currently on their team's roster, (3) participating at the varsity-level, (4) participating in an NCAA-sponsored sport, (5) and be at least 18 years of age.

\section{$\underline{\text { Data Collection }}$}

All data collection was performed at the Peter Stott Center, located on PSU's main campus. The Peter Stott Center is the main sports complex at PSU, housing all athletic teams and athletes.

This study used an original, hard-copy questionnaire to collect data regarding athletes' use, behaviors, and knowledge related to NSAIDs. The questionnaire was administered in paper form with the goals of increasing participation and minimizing non-compliance that can occur with an electronic survey. Questions for this survey were compiled from previously published research studies. Questions were refined through pilot testing and discussion with sports medicine professionals familiar with college athletes and NSAIDs. Questions were written in a neutral manner so that subjects did not feel coerced to answer questions in a certain manner. Questions were answered in "yes" or "no" fashion, as well as "check one" or "check all that apply." This was done to minimize the burden of answering long questions and increase the participation rate.

Questionnaires were administered for approximately four weeks in an attempt to survey as many athletes as possible. Athletes were approached by the researcher and 
asked if they would be willing to participate in the study. Athletes agreeing to participate were allowed to complete the questionnaire at their leisure and place of choosing. Subjects returned completed to the researcher (either immediately if they completed the survey in-person, or by appointment if they took the survey home) who then placed the completed document in a sealable folder. Surveys were handled only by the researcher and stored in a locked file cabinet located in the Peter Stott Center athletic training room. Athletes who did not complete surveys within the 4-week period were excluded from the study.

Consent for this study was implied (i.e., completion of a questionnaire by a participant implied that they consented to have their data used in this study). This method was applied in order to limit the amount of identifiable information participants provided. Implied-consent forms were attached to the front of each questionnaire and read by the participant before completing the survey. Consent forms detailed the purpose and risks involved in study participation, and also provided contact information if they wished to follow-up after the study was completed. Participants were encouraged to ask any questions they had before participating in the study.

The beginning of the survey instrument provided instructions on how to answer the questions. After reading the introduction, participants were asked to provide demographic information (i.e., date of birth, gender, year of eligibility, and sport). The remainder of the questionnaire contained 16 questions about their personal history of NSAID use as well as their current behaviors and attitudes towards NSAID use. Questions began by asking about the participant's general history of use (e.g., "Have you 
taken NSAIDs before in your lifetime?", "When did you start taking NSAIDs?"). The next set of questions asked participants about their NSAID use behaviors (e.g., "Do you take NSAIDs in-season or out-of-season?", "Do you use NSAIDs daily, monthly, or yearly?"). The final set of questions asked subjects about their attitudes and knowledge about NSAIDs (e.g., "What are your reasons for taking NSAIDs?”, “Are you aware of any adverse side-effects caused by NSAID?"). (See Appendix A for Survey Instrument) $\underline{\text { Variables }}$

The variables investigated in this study were based around demographic information, knowledge, attitudes, and behaviors related to the use of NSAIDs by collegiate athletes. Age, gender, year of eligibility, and sport were measured so that comparisons of NSAID use could be made. Participants were asked about their history of NSAID use: "Have they ever taken NSAIDs?", "When did they first take NSAIDs?", "How often have they taken NSAIDs since they first started using them?"; "Who influenced them to start taking NSAIDs", and "Why did they start taking NSAIDs". Answers to these questions allowed the researcher to compile information on prevalence of use, consistency of use, and reasons for use.

Participants were also asked about their attitudes and behaviors towards NSAIDs, specifically in relation to their sport: "Are you currently taking NSAIDs for reasons related to your sport?", "How often do you use NSAIDs while competing in-season?", How about while training in the off-season?", "What are your reasons for taking NSAIDs while competing in-season?", "What are your reasons for taking NSAIDs during the offseason?", and "How do you primarily receive your NSAIDs?". Answers to these 
questions helped the researcher determine if the athletes use NSAIDs with higher amounts of physical activity, under supervision, chronically, and for reasons indicated or contraindicated by research.

Participants were finally asked general questions about NSAIDs: "What is a typical dose of NSAIDs you take at a given time?", "Are you aware of any side-effects caused by NSAIDs?", and "Have you ever experienced any side-effects during sportsrelated activity you believed were caused by using NSAIDs?". Answers to these questions helped the researcher assess the participants' basic knowledge about and experience with NSAIDs, specifically dosage and side-effects.

$\underline{\text { Data Analysis }}$

At the end of the 4-week sampling period, data from the questionnaires were manually input into a Microsoft Excel spreadsheet. Data were then compiled and simple descriptive statistics were calculated (e.g., means, standard deviations, percentages). The data were organized into tables and figures, which are presented in the results section. 


\section{Chapter 4}

\section{Results}

A total of 79 PSU student-athletes completed questionnaires. Table 1 shows that of the 79 participants; 54 were male, most of whom were football players $(n=44)$, and 25 were female. It should be noted that data were collected from 9 sports teams, 3 of which were male sports teams (football, basketball, and cross country/track \& field) and 6 of which were female sports teams (cross country/track \& field, basketball, softball, volleyball, tennis, and soccer).

Table 1. Subject Descriptive Data

\begin{tabular}{|c|c|c|c|c|}
\hline & $\mathrm{n}$ & Age (yr) & Sport (n) & Eligibility (n) \\
\hline Male & 54 & $20.7 \pm 1.3$ & $\begin{array}{c}\text { FB - } 44 \\
\text { BSKB - } 3 \\
\text { CCTF - } 7\end{array}$ & $\begin{array}{c}\text { FR - } 9 \\
\text { SO - } 13 \\
\text { JR - } 19 \\
\text { SR - } 13\end{array}$ \\
\hline Female & 25 & $19.9 \pm 1.3$ & $\begin{array}{c}\text { CCTF - } 5 \\
\text { BSKB - } 3 \\
\text { SB - } 3 \\
\text { VB - } 4 \\
\text { TEN - } 3 \\
\text { SOC - } 7\end{array}$ & $\begin{array}{l}\text { FR - } 9 \\
\text { SO - } 4 \\
\text { JR - } 8 \\
\text { SR - } 4\end{array}$ \\
\hline Total & 79 & $20.5 \pm 1.3$ & $\begin{array}{c}\text { FB - } 44 \\
\text { BSKB - } 6 \\
\text { CCTF - } 12 \\
\text { SB - } 3 \\
\text { VB - } 4 \\
\text { TEN - } 3 \\
\text { SOC - } 7\end{array}$ & $\begin{array}{l}\text { FR - } 18 \\
\text { SO - } 17 \\
\text { JR - } 27 \\
\text { SR - } 17\end{array}$ \\
\hline
\end{tabular}

$\mathrm{n}=$ sample size, $\mathrm{FB}=$ Football, $\mathrm{BSKB}=$ Basketball, $\mathrm{CCTF}=$ Cross Country Track $\&$ Field, $\mathrm{SB}=$ Softball, $\mathrm{VB}=$ Volleyball, TEN $=$ Tennis, $\mathrm{SOC}=$ Soccer, $\mathrm{FR}=$ Freshman, $\mathrm{SO}=$ Sophomore, $\mathrm{JR}=$ Junior, $\mathrm{SR}=$ Senior. $($ mean $\pm \mathrm{sd})$ 
The survey response data for all questions can be found in Appendix D. Total sample data $(\mathrm{n} ; \%)$ are located in the first two columns, while data for males and females are located in columns 3-4 and 5-6, respectively. Responses to each question are grouped together and separated by alternating white and grey background. It should be noted that $100 \%$ of the athletes that participated in this study reported a history of NSAID use at some point in their lifetime.

Figure 1 depicts the summary of responses to question 2 ("When did you first use NSAIDs?"). Based on these results it appears that the majority of the athletes started taking NSAIDs before high school ( $72 \%$ of the males and $64 \%$ of the females started pre high school). A large percentage of males (39\%) and females (44\%) started taking NSAIDs even before middle school, which indicates that many of these athletes first used NSAIDs well before their teenage years. Although there were twice as many males as females, $16 \%$ of the females started taking NSAIDs in college, compared with only $2 \%$ of the males. These data indicate that females are more likely to start taking NSAIDs later than males. 


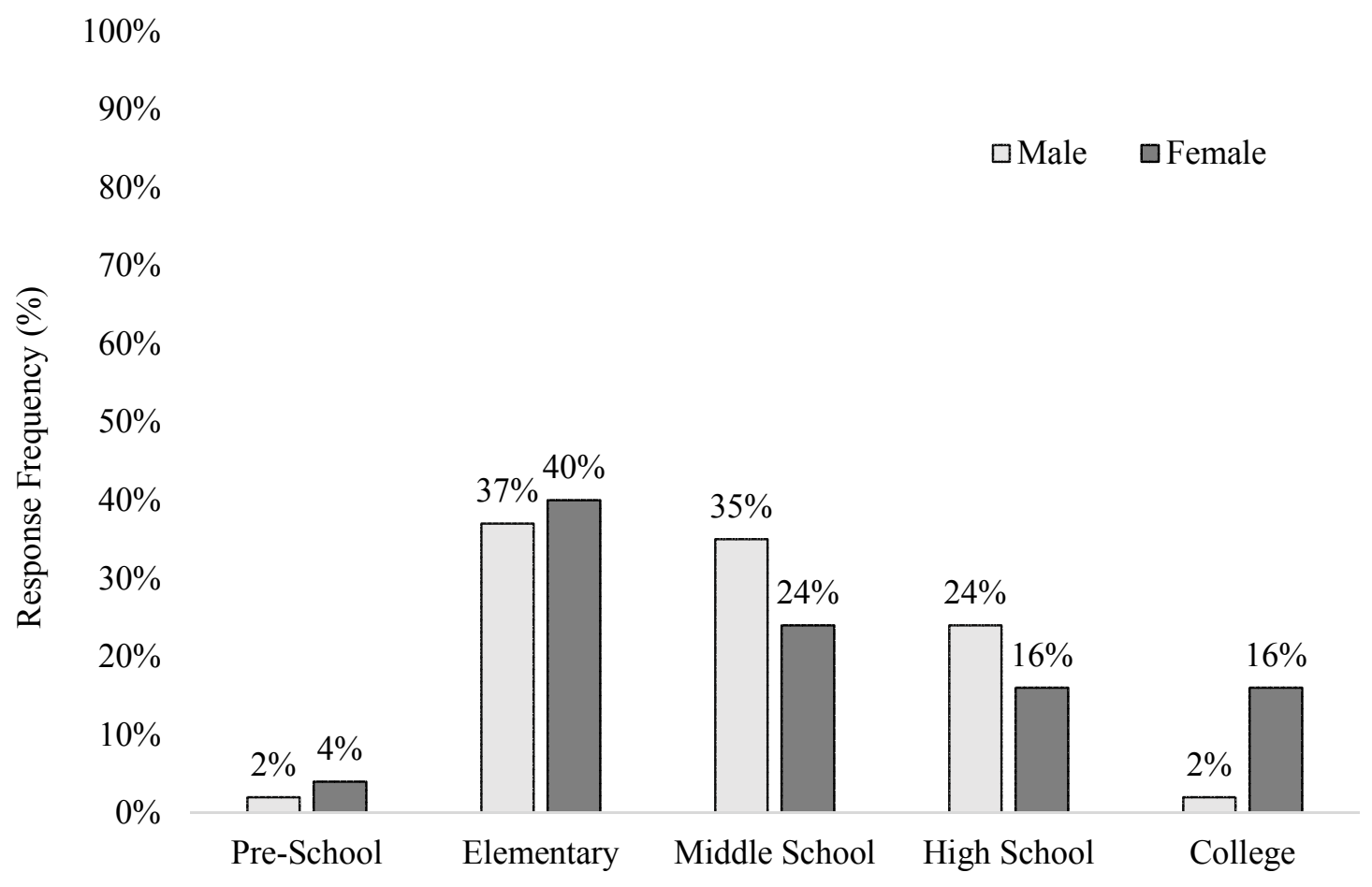

Figure 1. Summary of responses to question 2 ("When did you first use NSAIDs?").

Figure 2 shows the percentage of athletes that were currently (within the past week) taking or not taking NSAIDs at the time of this study. Data were obtained from question 5 ("Are you currently taking any NSAIDs?"). Also shown in Figure 2 is the percentage of athletes currently taking NSAIDs that were following a prescription. The data were obtained from question 6 ("Are you currently taking NSAIDs that were prescribed to you by a doctor or medical professional (Physical therapist, Athletic trainer, etc.)?" At the time of this study, $33 \%$ of males and $32 \%$ of females reported that they had been taking NSAIDs within the past week. Of the athletes that were currently taking NSAIDs, only half (16\%) of the females and approximately one-third $(9 \%)$ of males reported to be using NSAIDs that were prescribed to them by a health care professional. Based on these data, it appears that both male and female athletes in this 
sample may be more likely to use NSAIDs independently (without prescription from a health care professional).

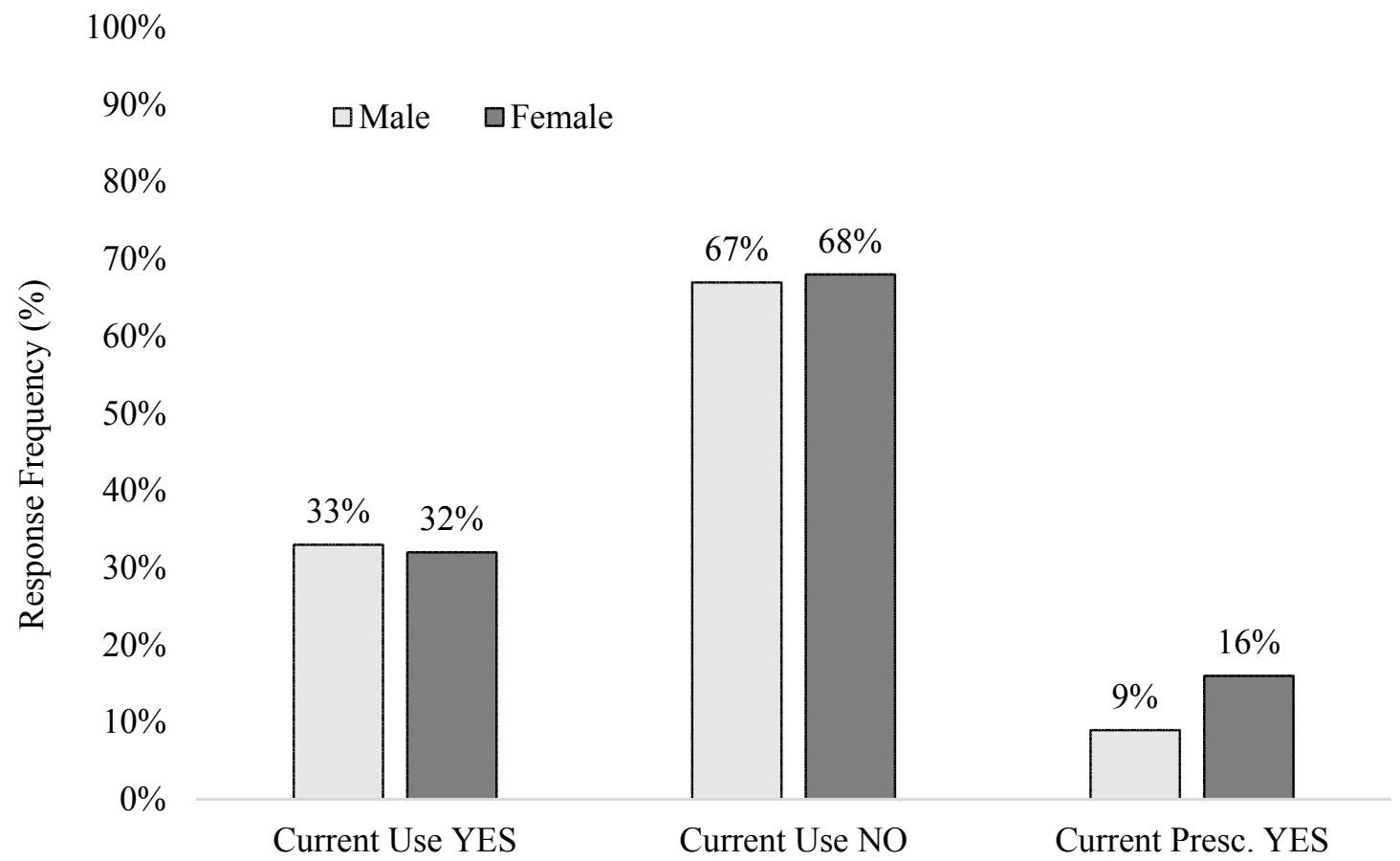

Figure 2. Summary of responses to question 5 ("Are you currently taking any NSAIDs?") and question 6 ("Are you currently taking NSAIDs that were prescribed to you by a doctor or medical professional (Physical therapist, Athletic trainer, etc.)?"

Figure 3 shows the summary responses to question 8 ("How often do you use NSAIDs while competing IN-SEASON?") and question 9 ("How often do you use NSAIDs while training in the OFF-SEASON?"). The frequency of NSAID use while athletes were in-season (IS) or off-season (OS) was categorized as frequently (3-7 days per week), regularly (1-2 days per week), infrequently (1-3 times per month), and never. Frequent use and regular use are considered to be high NSAID use, and the responses were combined. Infrequent use is considered to be low NSAID use. High in-season use of 
NSAIDs was reported by $52 \%$ of the male athletes and $48 \%$ of the female athletes, whereas off-season use was reported in $21 \%$ and $12 \%$ of the males and females, respectively. In males, the percentage of athletes reporting low use in-season (33\%) was nearly identical to those reporting low use off-season (32\%). A similar finding was noted for female athletes reporting low use in-season (40\%) and off-season (44\%). Fifteen percent of the male athletes reported never using NSAIDs in season, while 7\% reported never using NSAIDs off-season. The percentages of female athletes that reported never using NSAIDs were $12 \%$ in-season and $16 \%$ off-season.

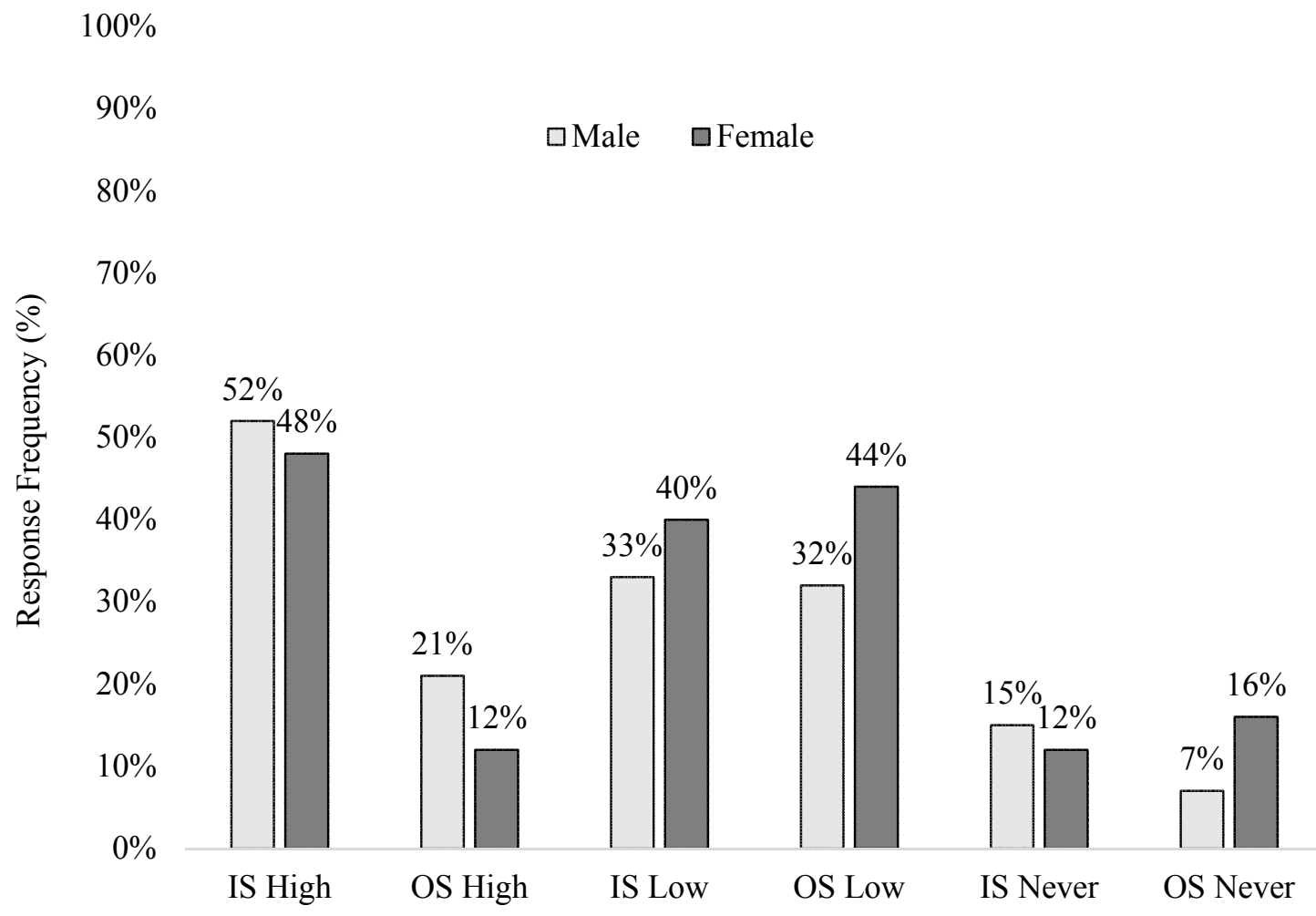

Figure 3. Summary of responses to question 8 ("How often do you use NSAIDs while competing IN-SEASON?"), and question 9 ("How often do you use NSAIDs while training in the $O F F-S E A S O N$ ?"). High = "Frequently" + "Regularly"; Low = "Infrequently" 
Based on these data it appears that high NSAID use in-season is greater than high NSAID use off-season in both male and female athletes. Low NSAID use in both males and females appears to be similar in-season and off-season. It is also apparent that more athletes use NSAIDs than those that do not. One answer not included in Figure 3 was the option "rarely" (off-season NSAID use only a few times per year). This option was not provided for the question regarding in-season use because the usual duration of competition is rarely longer than several months. Males reported rare NSAID use during the off-season $(41 \%)$, whereas $28 \%$ of the females reported rare use during the offseason. If off-season low NSAID use is defined as a combination of athletes reporting rare NSAID use during the off-season and athletes reporting infrequent use during the off-season, the percentage of males reporting low NSAID use is $73 \%$ and the percentage of females reporting low NSAID use is $72 \%$. This is a large percentage of athletes reporting low NSAID use during the off-season, which contrasts with the high NSAID use in-season use (males: 52\%; females: 48\%). These data suggests that the high NSAID use when athletes are in-season is due to the increased rigors of in-season competition.

Figure 4 shows summary responses to question 10 ("What are your reasons for using NSAIDs while competing IN-SEASON? ”) and question 11 (“What are your reasons for using NSAIDs while training in the OFF-SEASON? "). For this question athletes were asked to "choose all that apply," which is why percentages total greater than $100 \%$. The main reason given for both in-season and off-season NSAID use was for relief of pain due to injury (in-season: 76\% male, 72\% female; off-season: 57\% male, 64\% female). Other reasons included preventing injury or pain (in-season: $24 \%$ male, $36 \%$ female; off- 
season: $17 \%$ male, $20 \%$ female), soreness (in-season: $63 \%$ male, $40 \%$ female; off-season: $48 \%$ male, $32 \%$ female), recovery (in-season: $37 \%$ male, $20 \%$ female; off-season: $24 \%$ male, $12 \%$ female), and tightness (in-season: $24 \%$ male, $20 \%$ female; off-season: $17 \%$ male, $20 \%$ female). Athletes were also given the option to select "no NSAID use" inseason and off-season. No in-season NSAID use was reported by $11 \%$ of the males and $4 \%$ of the females. No off-season NSAID use for males and females was $20 \%$ and $8 \%$, respectively.

Reasons for NSAID use IS vs. OS seem to be similar with males and females. The most notable gender disparities between answers responses appear to be between IS soreness ( $23 \%$ difference), OS soreness ( $16 \%$ difference), and IS recovery ( $17 \%$ difference). While there is no obvious reason why these answers were largely different between males and females, some simple answers may be that males and females interpreted soreness differently, or males simply had more responses due to their larger sample size. There is a noticeable decline in answers when comparing IS responses to OS responses in both males and females. This data may further suggest that NSAID use IS is higher than NSAID use OS. 


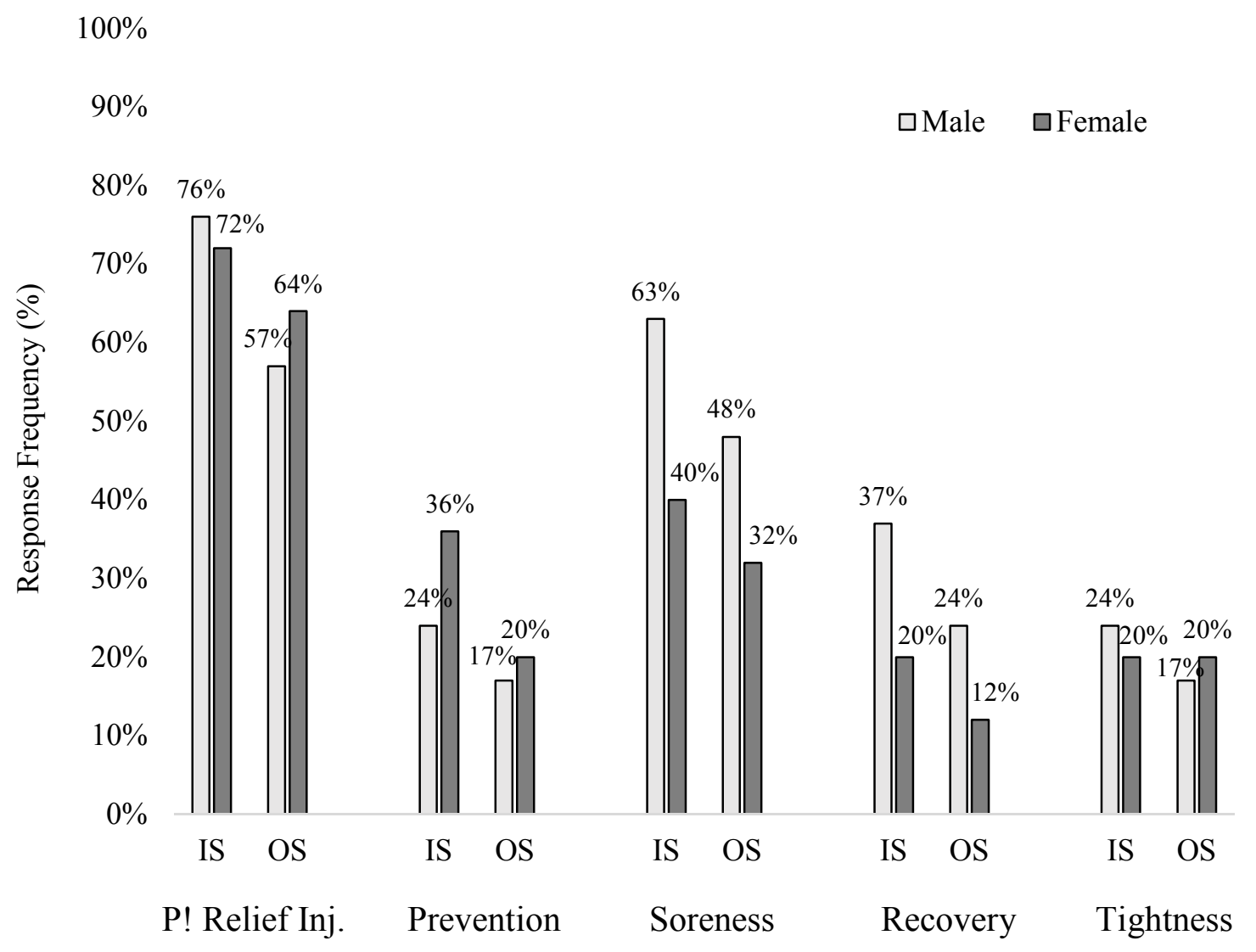

Figure 4. Summary of responses to question 10 ("What are your reasons for using NSAIDs while competing IN-SEASON?") and question 11 ("What are your reasons for using NSAIDs while training in the OFF-SEASON?").

Figure 5 shows the summary responses to question 12 ("From whom do you PRIMARILY receive your NSAIDs?"). The majority of athletes (59\% male; $52 \%$ female) appear to primarily obtain their NSAIDs through self-purchasing, presumably at popular retail stores. Athletes also reported obtaining NSAIDs from family members ( $22 \%$ male; $16 \%$ female $)$ and athletic trainers (15\% male; $20 \%$ female). Very few athletes reported that they primarily obtain their NSAIDs from peers, coaches, or doctors. 
In total, $83 \%$ of males and $76 \%$ of females reported that they obtain their NSAIDs primarily through means outside of health-care professionals, which further suggests a high amount of independent use and self-medication.

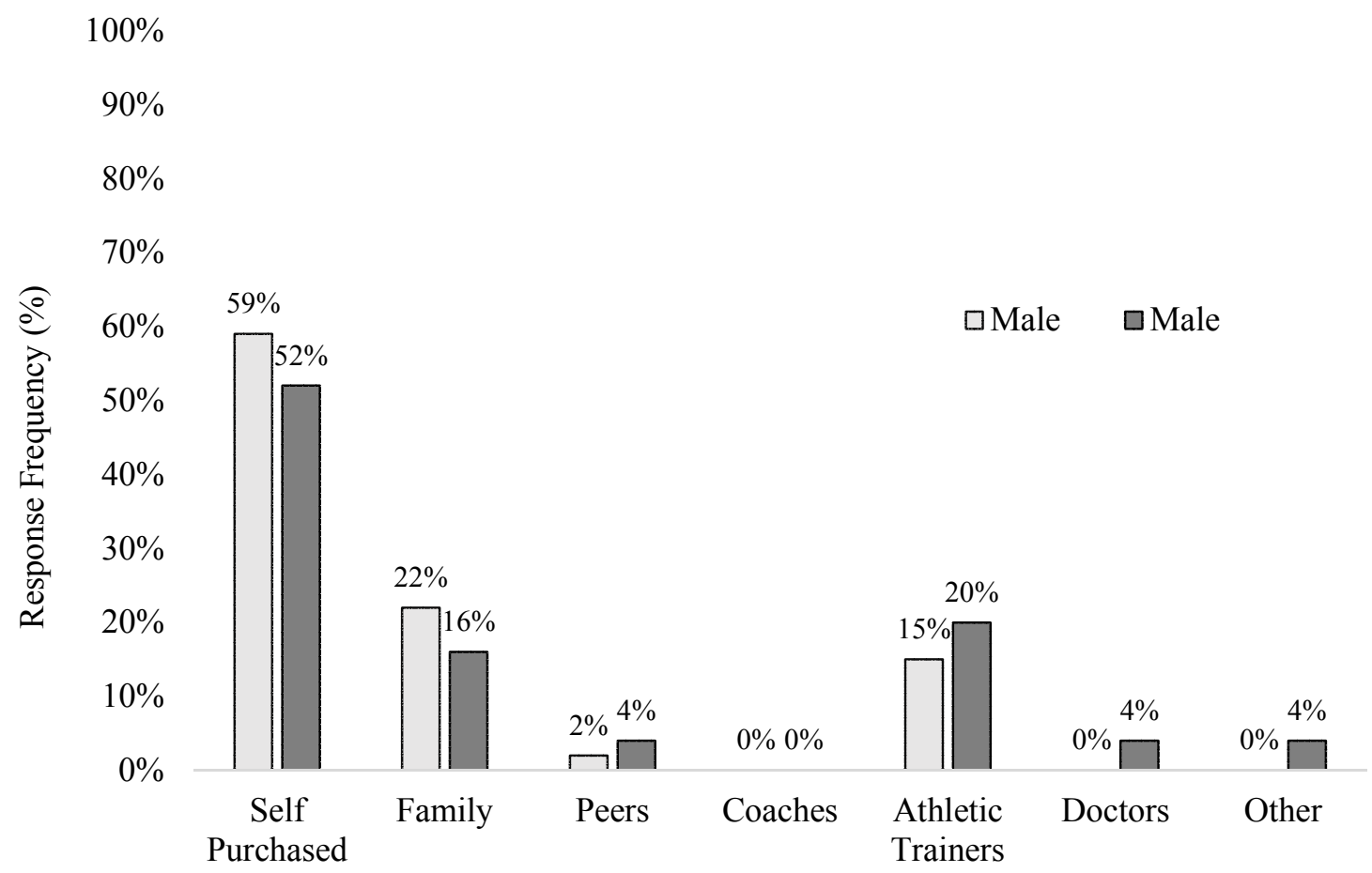

Figure 5. Summary of responses to question 12 ("From whom do you PRIMARILY receive your NSAIDs?').

Figure 6 illustrates summary responses to question 13 ("How do you TYPICALLY determine the dose of NSAIDs to take at a given time?"). Forty-one percent of the male athletes and $44 \%$ of the female athletes reported that they take doses of NSAIDs based on what the directions tell them to take. Some athletes indicated that the typical dose was determined on the basis of directions provided by athletic trainers $(20 \%$ male; $24 \%$ female). Others reported that the typical dose was based on the amount of pain and soreness experienced (28\% male; $28 \%$ female). Only $4 \%$ of the male athletes and $4 \%$ of 
the female athletes reported that the direction of a physician was used in determining a typical dose of NSAIDs.

Most athletes reported determining a NSAIDs based on the directions (presumably on the bottle label) or based on the level of pain and soreness they experienced (69\% male; $68 \%$ female), therefore it can be assumed that they are using NSAIDs from a self-purchased bottle. While this is not a certainty, most NSAIDs dispensed by health-care professionals are in packet form as a single dose; therefore, dosage instructions are not necessary. This data further suggests independent and indiscriminate use of NSAIDs by athletes without supervision.

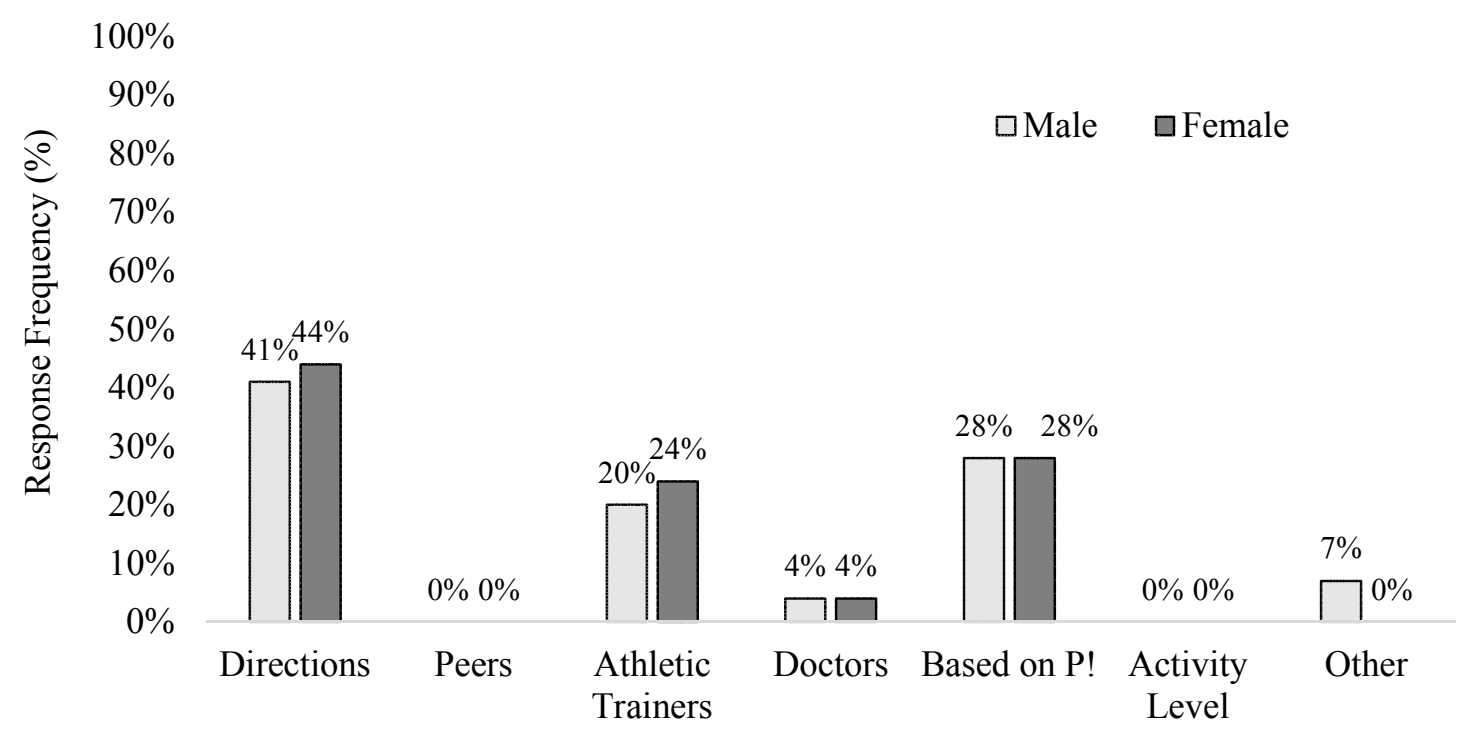

Figure 6. Summary of responses to question 13 ("How do you TYPICALLY determine the dose of NSAIDs to take at a given time?").

Figure 7 shows the summary of responses to question 15 ("Have you heard of NSAIDs causing any side effects?"). An overwhelming majority of athletes ( $83 \%$ male; $76 \%$ female) were not aware of any side-effects from taking NSAIDs. Only $17 \%$ of male 
athletes and $24 \%$ of female athletes were aware of any side-effects from taking NSAIDs. These data suggest that most athletes are taking NSAIDs unaware of any associated risks.

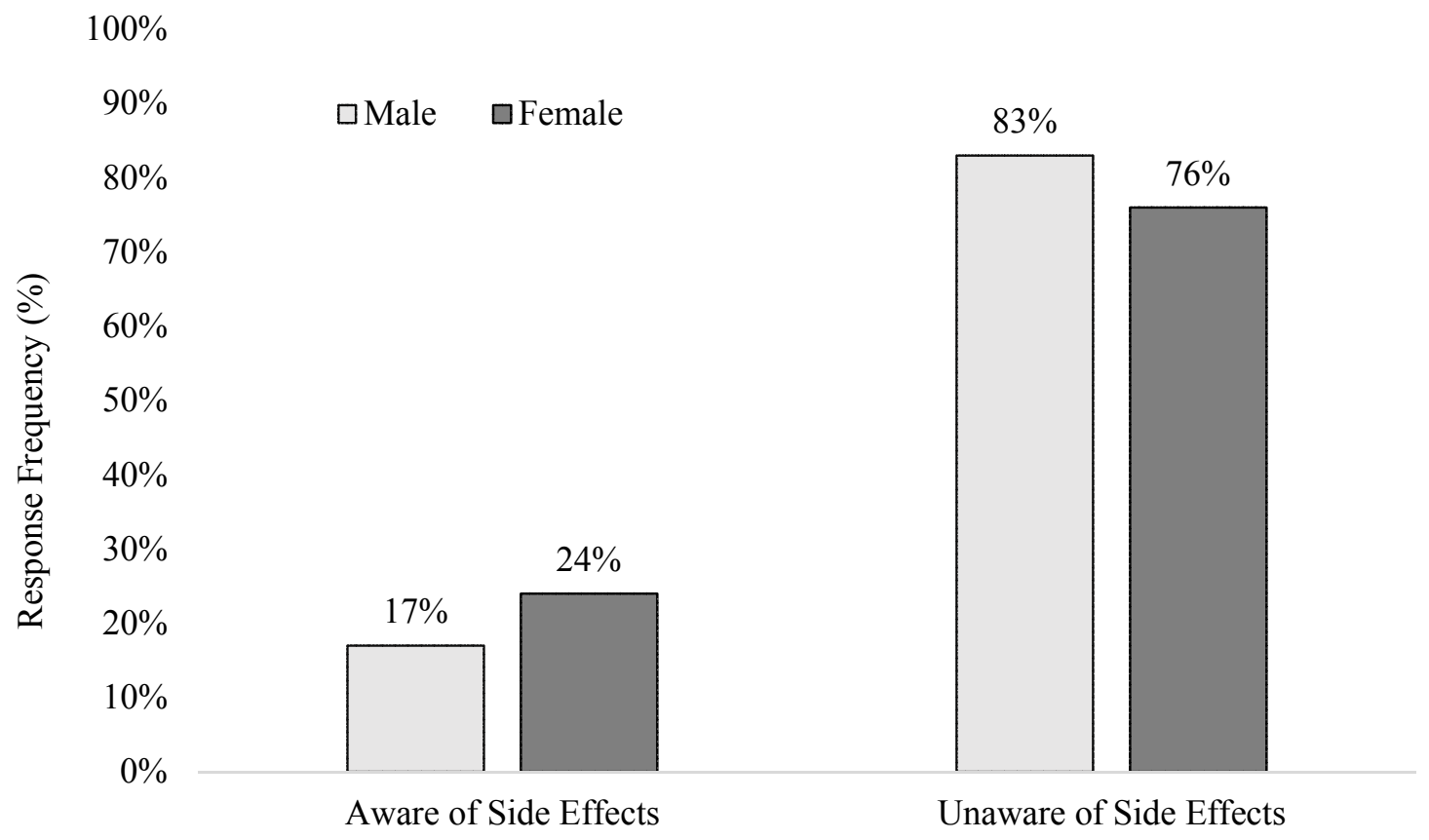

Figure 7. Summary of responses to question 15 ("Have you heard of NSAIDs causing any side effects?"). 


\section{Chapter 5}

\section{Discussion}

This study was performed to investigate NSAID use in Division I collegiate athletes. To date, few studies in this population have been published, and the results of this study add to the body of knowledge about NSAID use in collegiate athletes. In one recent study, Holmes et al. (2013) investigated the prevalence of NSAID use among collegiate football players and found that $95.7 \%$ had used NSAIDs at some point in their lives. The current study supports these findings with $100 \%$ of athletes reporting NSAID use at some point in their life. Holmes et al. (2013) also reported a high percentage of early NSAID use in which athletes reported first using NSAIDs as early as middle school (45.6\%). Athletes from the current study also reported a significant percentage of early NSAID use, with the majority of athletes reporting NSAID use as early as elementary school (37\% male; 40\% female). Additionally, athletes in the Holmes et al. (2013) study reported obtaining NSAIDs from a variety of sources, the majority (81\%) of whom reported that they obtained NSAIDs through self-purchasing. Although the current study differed from the Holmes et al. (2013) study by asking athletes about their primary sources of NSAIDs rather than all of the sources, there were similar findings in which the majority of athletes (59\% of males; $52 \%$ of females) reported self-purchasing as their primary method of obtaining NSAIDs.

Finally, Holmes et al. (2013) found that $50 \%$ of athletes reported high (daily or weekly) NSAID use in-season compared to $14.6 \%$ reporting high NSAID use during the off-season. The current study provided similar findings, with 52\% of male athletes and 
$48 \%$ of female athletes reported high NSAID use in-season compared with $21 \%$ of male athletes and $12 \%$ of female athletes who reported high off-season NSAID use. Both studies found a higher percentage of high use of NSAIDs when athletes are in-season and a lower percentage of high-use when they are off-season. Both studies also appear to have found a high percentage of athletes starting NSAID use at an early age while also obtaining the majority NSAIDs from sources other than health care professionals.

The current study found that $33 \%$ of males and $32 \%$ of females had been taking NSAIDs within the past week, while only $16 \%$ of the females and $9 \%$ of males reported using NSAIDs that were prescribed to them. This suggests that male and female collegiate athletes may be predisposed to use NSAIDs without prescription from a health care professional. As previously mentioned, a large percentage of both male and female athletes reported high-use of NSAIDs in-season while reporting high amounts of low to minimal-use off-season. Based on these data and previous studies, it appears that both male and female athletes are likely using NSAIDs at increased frequencies in-season due to the increased rigors of in-season training and competition. This notion was further supported when athletes were asked about the reasons they use NSAIDs in-season and off-season.

Athletes reported that their main reason for in-season and off-season NSAID use was for pain relief due to injury, but also reported high response rates for prophylactic use, DOMS, recovery, and general muscle tightness. Response rates for each option were higher in-season than off-season, which may further support higher in-season use of NSAIDs due to the increased physical demands of in-season competition. This 
information also demonstrated that athletes are likely using NSAIDs outside of their intended use.

Study reviews on proper NSAID use guidelines (Warden, 2009; Ziltener et al., 2010) seem to agree that short-term (less than 7 days) use of NSAIDs in the presence of certain injuries can be effective in the treatment of pain and inflammation without highrisk of experiencing adverse events. While this may be true, many of the athletes in this study reported high-use of NSAIDs for the duration of their entire sports seasons, thus putting them at an increased risk of experiencing adverse events (Gabriel, Jaakkimainen, \& Bombardier, 1991; Huerta et al., 2005; Lanier, 2004). Although taking NSAIDs prophylactically and for recovery may seem like a logical strategy to many athletes, there is no definitive literature supporting or refuting the use of NSAIDs for delayed-onset muscle soreness (DOMS). Much of the literature, however, contraindicates prophylactic use of NSAIDs (Alaranta et al., 2008; Baker et al., 2005; Joslin et al., 2013; Van Wijck et al. 2012; Warden, 2009).

Additionally, this study found that the majority of athletes (83\% male; $76 \%$ female) were not aware of any side-effects of NSAID use, suggesting that many athletes are taking NSAIDs unaware of any associated risks. Most of the athletes in this study reported that they obtain their NSAIDs primarily through means outside of health-care professionals and reported taking doses based on the level of pain and soreness they experienced. These data further suggest independent and indiscriminate use of NSAIDs by athletes without supervision. These findings, combined with a high amount of high- 
use of NSAIDs for reasons outside of their intended use, may further increase the risk of adverse events.

Another goal of this study was to investigate NSAID use by gender and sport. Behaviors and attitudes around NSAID use were very similar between male and female athletes in this study. However, there were several gender differences of note. Despite there being twice as many male participants as female athletes, $16 \%$ of the female athletes started taking NSAIDs in college compared to $2 \%$ of the male athletes. This suggests that female athletes start taking NSAIDs later in their athletic careers. Another gender difference appeared to be in the athletes' reasons for NSAID use: IS soreness (males: 63\%; females: $40 \%$ ), OS soreness (males: $48 \%$; females: $32 \%$ ), and IS recovery (males: $37 \%$; females: $20 \%$ ). While there is no apparent reason for this difference, it may be because males and females interpreted soreness differently.

Unfortunately, this study was unable to obtain enough data to make inferences about sport-specific NSAID use. However, because football players represented a substantial proportion of the sample (44 out of 79 participants), the current study provides potentially useful information about NSAID use in football players. Similar to the Holmes et al. (2013) study, the current study found a high prevalence of high-use of NSAIDs. Of the 44 football players, 13 (30\%), reported current (within the past week) use of NSAIDs, while only $5(11 \%)$ of the players reported to have been prescribed NSAIDs. In-season use of NSAIDs was high in 21 (48\%) of the players, but in only 6 $(14 \%)$ of the players during the off-season, again showing a common trend in high prevalence of high use in-season compared to a low prevalence of high use off-season. 
Also in line with the Holmes et al. (2013) study, $80 \%$ of players reported that they obtained NSAIDs from sources other than health-care professionals; indicating a likelihood of indiscriminate and unsupervised use. Finally, $89 \%$ of the football players were unaware of any side-effects of NSAID use, indicating a general lack of knowledge of NSAIDs.

\section{$\underline{\text { Limitations }}$}

This study had several limitations that should be noted. It was a cross-sectional survey, and was limited to a convenience sample of participants. Also, the extent to which participants may have answered questions in a socially desirable manner is not known. However, all participants were encouraged to respond to questions truthfully. Because this study took place at a single institution over a short period of time, the results may not be generalizable to other institutions or populations. It is also possible that the results to this study may not be generalizable simply due to a relatively small sample size. It was originally thought that data could be obtained from all 291 student-athletes via team meetings. However, due to the timing of this study, most sports teams were offseason and it was difficult to arrange data collection on a group basis. Therefore, athletes were contacted individually to complete the surveys.

\section{$\underline{\text { Conclusion }}$}

In summary, this study revealed a pattern of high NSAID use in athletes competing in-season compared to high amounts of low NSAID use in athletes off-season. It also revealed a high amount of non-prescription NSAID use. There was a high prevalence of self-purchasing of NSAIDs, combined with self-medication. Furthermore, 
athletes demonstrated a long history of NSAID use, with a majority of athletes reporting that they began using NSAIDs well before high school. This study also revealed a general lack of knowledge about NSAIDs as most athletes reported taking these drugs for reasons outside their intended use and without much awareness of potential side-effects.

Future studies should be conducted in a longitudinal manner to more clearly understand the true prevalence of NSAID use in athletes. More studies need to be performed on larger samples with diverse athlete populations. This would help provide a deeper understanding of potential differences in NSAID use between genders, sports, and social backgrounds. Finally, additional research could help to increase the awareness and education of athletes and their health-care professionals about the proper use and potential negative effects of NSAIDs. 


\section{References}

Akermark, C., \& Forsskahl, B. (1990). Topical indomethacin in overuse injuries in athletes: A randomized double blind comparing elmetacin with oral indomethacin and placebo. International Journal of Sports Medicine, 11, 393-396.

Alaranta, A., Alaranta, H., \& Helenius, I. (2008). Use of prescription drugs in athletes. Sports Medicine, 38(6), 449-463.

Almekinders, L. C., \& Gilbert, J. A. (1986). Healing of experimental muscle strains and the effects of nonsteroidal anti-inflammatory medication. The American Journal of Sports Medicine, 14(4), 303-308

Almekinders, L. C. (1999). Anti-inflammatory treatment of muscular injuries in sport. Sports Medicine, 28(6), 383-388.

Baker, J., Cotter, J. D., Gerrard, D. F., Bell, M. L., \& Walker, R. J. (2005). Effects of indomethacin and celecoxib on renal function in athletes. Medicine \& Science in Sports \& Exercise, 37(5), 712-717.

Baldwin, A. C., Stevenson, S. W., \& Dudley, G. A. (2001). Non-steroidal antiinflammatory therapy after eccentric exercise in healthy older individuals. Journal of Gerontology: Biological Sciences, 56(8), M510-513.

Barnett, A. (2006). Using recovery modalities between training sessions in elite athletes. Sports Medicine, 36(9), 781-796.

Baron, J. A., Sandler, R. S., Bresalier, R. S., Lanas, A., Morton, D. G., Riddell, R.,...DeMets, D. L. (2008). Cardiovascular events associated with rofecoxib: Final analysis of the APPROVe trial. The Lancet, 372, 1756-1764. 
Barozzi, N., \& Tett, S. E. (2008). Non-steroidal anti-inflammatory drugs, cyclooxygenase-2 inhibitors and paracetamol use in Queensland and in the whole of Australia. BMC Health Services Research, 8, 196.

Bavry, A. A., Khaliq, A., Gong, Y., Handberg, E. M., Cooper-DeHoff, R. M., \& Pepine, C. J. (2011). Harmful effects of NSAIDs among patients with hypertension and coronary artery disease. American Journal of Medicine, 124(7), 614-620.

Berglund, B., \& Sundot-Borgen, J. (2001). Sports medicine update. Scandinavian Journal of Medicine \& Science in Sports, 11(6), 369-371.

Brickson, S., Ji, L.L., Schell, K., Olabisi, R., Schneider, B. S. P., \& Best, T. M. (2003). M1/70 attenuates blood-borne neutrophil oxidants, activation, and myofiber damage following stretch injury. Journal of Applied Physiology, 95(3), 969-976.

Brown, K. M., Saunders, M. M., Kirsch, T., Donahue, H. H., \& Reid, J. S. (2004). Effect of cox-2-specific inhibition of fracture-healing in the rat femur. Journal of Bone \& Joint Surgery, 86(1), 116-123.

Bush, P. J., \& Rabin, D. L. (1976). Who's using non-prescribed medicines? Medical Care, 14, 1014-1023.

Buvanendran, A., Kroin, J. S., Tuman, K. J., Lubenow, T. R., Elmofty, D., Moric, M., \& Rosenberg, A. G. (2003). Effects of perioperative administration of a selective cyclooxygenase 2 inhibitor on pain management and recovery of function after knee replacement: A randomized controlled trial. Journal of the American Medical Association, 290(18), 2411-2418. 
Chambers, C. T., Reid, G. J., McGrath, P. J., \& Finley, G. A. (1997). Self-administration of over-the-counter medication for pain among adolescents. Archives of Pediatrics \& Adolescent Medicine, 151(5), 449-455.

Correa, C. S., Cadore, E. L., Bijoldo, J. M., Ramos da Silva, E., Pinto, R. S., Reischak de Oliveira, A., \& Kruel, L. F. M. (2012). The effects of ibuprofen on muscle performance, workload and plasma creatine kinase during a strength training session. Medicina Sportiva, 16(1), 17-21.

Corrigan, B, \& Kazlauskas, R. (2003). Medication use in athletes selected for doping control at the Sydney Olympics (2000). Clinical Journal of Sports Medicine, 13, $33-40$.

Couzin, J. (2004). Drug safety: Withdrawal of Vioxx casts a shadow over COX-2 inhibitors. Science, 306, 384-385.

Crofford, L. J. (1997). COX-1 and COX-2 tissue expression: Implications and predictions. Journal of Rheumatology, 49, 15-19.

Da Silva, E. R., De Rose, E. H., Ribeiro, J. P., Sampedro, L. B. R., Devos, D. V., Ferreira, A. O., \& Kruel, L. F. M. (2011). Non-steroidal anti-inflammatory use in the XV Pan-American Games (2007). British Journal of Sports Medicine, 45, 9194.

Donnelley, A. E., McCormick, K., Maughan, R. J., Whiting, P. H., \& Clarkson, P. M. (1988). Effects of a non-steroidal anti-inflammatory drug on delayed onset muscle soreness and indices of damage. British Journal of Sports Medicine, 22, 325-328. 
Donnelly, A. E., Maughan, R. J., \& Whiting, P. H. (1990). Effects of ibuprofen on exercise-induced muscle soreness and indices of muscle damage. British Journal of Sports Medicine, 24, 191-195.

Dudley, G. A., Czerkawski, J., Meinrod, A., Gillis, G., Baldwin, A., \& Scarpone, M. (1997). Efficacy of naproxen sodium for exercise-induced dysfunction muscle injury and soreness. Clinical Journal of Sports Medicine, 7(1), 3-10.

Ekman, E. F., Fiechtner, J. J., Levy, S., \& Fort, J. G. (2002). Efficacy of celecoxib versus ibuprofen in the treatment of acute pain: A multicenter, double-blind, randomized controlled trial in acute ankle sprain. American Journal of Orthopedics, 31(8), 445-451.

Elder, C. L., Dahners, L. E., \& Weinhold, P. S. (2001). A cyclooxygenase-2 inhibitor impairs ligament healing in the rat. American Journal of Sports Medicine, 29(6), 801-805.

Endo, K., Sairyo, K., Komatsubara, S., Sasa, T., Egawa, H., Yonekura, D.,...Yasui, N. (2002). Cyclooxygenase-2 inhibitor inhibits the fracture healing. Journal of Physiological Anthropology and Applied Human Science, 21(5), 235-238.

Francis, K. T., \& Hoobler, T. (1987). Effects of aspirin on delayed muscle soreness. Journal of Sports Medicine and Physical Fitness, 27(3), 333-337.

Fitzgerald, G. A. (2004). Coxibs and cardiovascular disease. New England Journal of Medicine, 351(17), 1709-1711.

Frantz, S. (2004). Vioxx risk could signify trouble in class. Nature Reviews Drug Discovery, 3(11), 899-901. 
Gabriel, S. E., Jaakkimainen, L., \& Bombardier, C. (1991). Risk for serious gastrointestinal complications related to use of nonsteroidal anti-inflammatory drugs: A meta-analysis. Annals of Internal Medicine, 115(10), 787-796.

Galer, B. S., Rowbotham, M., Perander, J., Devers, A., \& Friedman, E. (2000). Topical diclofenac patch relieves minor sports injury pain: Results of a multicenter controlled clinical trial. Journal of Pain and Symptom Management, 19(4), 287294.

Gerstenfeld, L. C., Thiede, M., Seibert, K., Mielke, C., Phipphard, D., Svagr, B.,...Einhorn, T. A. (2003). Differential inhibition of fracture healing by nonselective and cyclooxygenase-2 selective non-steroidal anti-inflammatory drugs. Journal of Orthopaedic Research, 21(4), 670-675.

Gilroy, D. W., Colville-Nash, P. R., Willis, D., Chivers, J., Paul-Clark, M. J., \& Willoughby, D. A. (1999). Inducible cyclooxygenase may have anti-inflammatory properties. Nature Medicine, 5, 698-701.

Gorski, T., Cadore, E. L., Pinto, S. S., Marczwski da Silva, E., Correa, C. S., Beltrami, F. G., \& Kruel, L. F. M. (2011). Use of NSAIDs in triathletes: Prevalence, level of awareness and reasons for use. British Journal of Sports Medicine, 45(2), 85-90.

Graham, D. J., Campen, D., Hui, R., Spence, M., Cheetham, C., Levy, G.,...Graham, D. (2005). Risk of acute myocardial infarction and sudden cardiac death in patients treated with cyclo-oxygenase 2 selective and non-selective non-steroidal antiinflammatory drugs: Nested case-control study. The Lancet, 365, 475-481. 
Griffiths, M. L. (1992). End-stage renal failure caused by regular use of antiinflammatory analgesic medication for minor sports injuries. A case report. South African Medical Journal, 81(7), 377-378.

Grossman, J. M., Arnold, B. L., Perrin, D. H., \& Kahler, D. M. (1995). Effect of ibuprofen use on delayed onset muscle soreness of the elbow flexors. Journal of Sport Rehabilitation, 4, 253-263.

Hasson, S. M., Daniels, J. C., Divine, J. G., Niebuhr, B. R., Richmond, S., Stein, P. G., \& Williams, J. H. (1993). Effect of ibuprofen use on muscle soreness, damage, and performance: A preliminary investigation. Medicine \& Science in Sports \& Exercise, 25(1), 9-17.

Hawke, T. J., \& Garry, D. J. (2001). Myogenic satellite cells: Physiology to molecular biology. Journal of Applied Physiology, 91, 534-551.

Holmes, N., Cronholm, P. F., Duffy, A. J., \& Webner, D. (2013). Nonsteroidal antiinflammatory drug use in collegiate football players. Clinical Journal of Sports Medicine, 23, 283-286.

Howell, J. N., Conaster, R. R., Chleboun, G. S., Karapondo, D. L., \& Chila, A. G. (1998a). The effect of nonsteroidal anti-inflammatory drugs on recovery from exercise-induced muscle injury 1. Flurbiprofen. Journal of Musculoskeletal Pain, 6(4), 59-68.

Howell, J. N., Conaster, R. R., Chleboun, G. S., Karapondo, D. L., \& Chila, A. G. (1998b). The effect of nonsteroidal anti-inflammatory drugs on recovery from 
exercise-induced muscle injury 2. Ibuprofen. Journal of Musculoskeletal Pain, 6(4), 69-83.

Huang, S. H., Johnson, K., \& Pipe, A. L. (2006). The use of dietary supplements and medications by Canadian athletes at the Atlanta and Sydney Olympic Games. Clinical Journal of Sport Medicine, 16(1), 27-33.

Huerta, C., Castellsague, J., Varas-Lorenzo, C., \& Rodriguez, L. A. (2005). Nonsteroidal anti-inflammatory drugs and risk of ARF in the general population. American Journal of Kidney Diseases, 45(3), 531-539.

Jarvinen, M., Lehto, M., \& Sorvari, T. (1992). Effect of some anti-inflammatory agents on the healing of ruptured muscles. Journal of Sports Traumatology and Related Research, 14, 19-28.

Joslin, J., Lloyd, J. B., Kotlyar, T., \& Wojcik, S. M. (2013). NSAID and other analgesic use by endurance runners during training, competition and recovery. South African Journal of Sports Medicine, 25(4), 101-104.

Kohn, R., \& White K. L. (Eds.). (1976). Health Care an International Study. New York, NY: Oxford University Press.

Krentz, J. R., Quest, B., Farthing, J. P., Quest, D. W., \& Chilibeck, P. D. (2008). The effects of ibuprofen on muscle hypertrophy, strength, and soreness during resistance training. Applied Physiology, Nutrition, and Metabolism, 33(3), 470475. 
Kuipers, H., Keizer, H. A., Verstappen, F. T., \& Costill, D. L. (1985). Influence of a prostaglandin-inhibiting drug on muscle soreness after eccentric work. International Journal of Sports Medicine, 6, 336-339.

Lanier, A. B. (2004). Treating DOMS in sport with NSAIDs. International SportMed Journal, 5(2), 129-140.

Lapointe, B. M., Fremont, P., \& Cote, C. H. (2002). Adaptation to lengthening contractions is independent of voluntary muscle recruitment but relies on inflammation. American Journal of Physiology - Regulatory, Integrative, and Comparative Physiology, 282(1), R323-329.

Lapointe, B. M., Fremont, P., \& Cote C. H. (2003). Influence of nonsteroidal antiinflammatory drug treatment duration and time of onset on recovery from exercise-induced muscle damage in rats. Archives of Physical Medicine and Rehabilitation, 84(4), 651-655.

Lecomte, J. M., Lacroix, V. J., Montgomery, D. L. (1998). A randomized controlled trial of the effect of naproxen on delayed onset muscle soreness and muscle strength. Clinical Journal of Sports Medicine, 8(2), 82-87.

Leufkens, H. G., Ameling, C. B., Hekster, Y. A., \& Bakker, A. (1990). Utilization patterns of non-steroidal anti-inflammatory drugs in an open Dutch population. Pharmaceutisch Weekblad, 12(3), 97-103.

Lieber, R. L., \& Friden, J. (2002). Morphologic and mechanical basis of delayed-onset muscle soreness. Journal of the American Academy of Orthopaedic Surgeons, 10, $67-73$ 
Mackey, A. L., Kjaer, M., Dandanell, S., Mikkelsen, K. H., Holm, L., Dossing, S.,... Langberg, H. (2007). The influence of anti-inflammatory medication on exerciseinduced myogenic precursor cell responses in humans. Journal of Applied Physiology, 103, 425-431.

Mackey, A. L., Mikkelsen, U. R., Magnusson, S. P., \& Kjaer, M. (2012). Rehabilitation of muscle after injury - the role of anti-inflammatory drugs. Scandinavian Journal of Medicine \& Science in Sports, 22, 8-14.

Mackey, A. L. (2013). Role of inflammation in skeletal muscle, connective tissue, and exertional injuries: To block or not to block? Journal of Applied Physiology, 115, 900-908.

Mamdani, M., Jurrlink, D., Lee, D., Rochon, P. A., Kopp, A., Naglie, G.,...Stukel, T. A. (2004). Cyclo-oxygenase-2 inhibitors versus non-selective non-steroidal antiinflammatory drugs and congestive heart failure outcomes in elderly patients: A population-based cohort study. The Lancet, 363, 1751-1756.

Martin, M. J., Jimenez, M. D., \& Motilva, V. (2001). New issues about nitric oxide and its effect on the gastrointestinal tract. Current Pharmaceutical Design, 7(10). 881908.

Mazieres, B., Rouanet, S., Velicy, J., Scarsi, C., \& Reiner, V. (2005). Topical ketoprofen patch $(100 \mathrm{mg})$ for the treatment of ankle sprain. American Journal of Sports Medicine, 33(4), 515-528.

Mishra, D. K., Friden, J., Schmitz, M. C., \& Lieber, R. L. (1995). Anti-inflammatory medication after muscle injury: A treatment resulting in short-term improvement 
but subsequent loss of muscle function. Journal of Bone and Joint Surgery, 77(10), 1510-1519.

Moore, R. A., Tramer, M. R., Carroll, D., Wiffen, P. J., \& McQuay, H. J. (1998).

Quantitative systematic review of topically applied non-steroidal antiinflammatory drugs. $B M J, 316,333-338$.

Moore, N. (2007). Ibuprofen: A journey from prescription to over-the-counter use. Journal of the Royal Society of Medicine, 100, 2-6.

Moran, M. (1991). Double-blind comparison of diclofenac potassium, ibuprofen and placebo in the treatment of ankle sprains. Journal of International Medical Research, 19, 121-130.

Obremsky, W. T., Seaber, A. V., Ribbeck, B. M., \& Garrett, W. E. (1994).

Biomechanical and histologic assessment of a controlled muscle strain injury treated with piroxicam. American Journal of Sports Medicine, 22(4), 558-561.

O’Grady, M., Hackney, A. C., Schneider, K, Bossen, E., Steinberg, K., Douglas, J. M., ...Watkins, W. D. (2000). Diclofenac sodium (voltaren) reduced exercise-induced injury in human skeletal muscle. Medicine \& Science in Sports \& Exercise, 32(7), 1191-1196.

Page, J., \& Henry, D. (2000). Consumption of NSAIDs and the development of congestive heart failure in elderly patients: An underrecognized public health problem. Archives of Internal Medicine, 160(6), 777-784.

Page, A. J., Reid, S. A., Speedy, D. B., Mulligan, G. P., \& Thompson, J. (2007). Exercise-associated hyponatremia, renal function, and nonsteroidal 
antiinflammatory drug use in an ultraendurance mountain run. Clinical Journal of Sport Medicine, 17(1), 43-48.

Paoloni, J. A., Milne, C., Orchard, J., \& Hamilton, B. (2010). Non-steroidal antiinflammatory drugs in sports medicine: Guidelines for practical but sensible use. South African Journal of Sports Medicine, 22(1), 20-22.

Peterson, J. M., Trappe, T. A., Mylona, E., White, F., Lambert, C. P., Evan, W. J., \& Pizza, F. X. (2003). Ibuprofen and acetaminophen: Effect of muscle inflammation after eccentric exercise. Medicine \& Science in Sports \& Exercise, 35(6), 892-896

Pizza, F. X., Cavender, D., Stockard, A., Baylies, H., \& Beighle, A. (1999). Antiinflammatory doses of ibuprofen: Effect on neutrophils and exercise-induced muscle injury. International Journal of Sports Medicine, 20(2), 98-102.

Rahusen, F. T. G., Weinhold, P. S., \& Almekinders, L. C. (2004). Nonsteroidal antiinflammatory drugs and acetaminophen in the treatment of an acute muscle injury. American Journal of Sports Medicine, 32(8), 1856-1859.

Rankin, J. A. (2004). Biological mediators of acute inflammation. Advanced Clinical Issues: Advanced Practice in Acute \& Critical Care, 15(1), 3-17.

Reynolds, J. F., Noakes, T. D., Schwellnus, M. P., Windt, A., \& Bowerbank, P. (1995). Non-steroidal anti-inflammatory drugs fail to enhance healing of acute hamstring injuries treated with physiotherapy. South African Medical Journal, 85(6), 517522. 
Rodriguez, L. A. G., \& Tolosa, L. B. (2007). Risk of upper gastrointestinal complications among users of traditional NSAIDs and COXIBs in the general population. Gastroenterology, 132(2), 498-506.

Sayers, S. P., Knight, C. A., Clarkson, P. M., Van Wegen, E. H., \& Kamen, G. (2000). Effect of ketoprofen on muscle function and sEMG activity after eccentric exercise. Medicine \& Science in Sports \& Exercise, 33(5), 702-710.

Schultz, E., \& McCormick, K. M. (1994). Skeletal muscle satellite cells. Reviews of Physiology, Biochemistry and Pharmacology, 123, 213-257.

Semark, A., Noakes, T. D., St. Clair-Gibson, A., \& Lambert, M. I. (1999). The effect of a prophylactic dose of flurbiprofen on muscle soreness and sprinting performance in trained subjects. Journal of Sports Sciences, 17(3), 197-203.

Simon, A. M., Manigrasso, M. B., \& O’Connor, J. P. (2002). Cyclo-oxygenase 2 function is essential for bone fracture healing. Journal of Bone \& Mineral Research, 17, 963-976.

Singh, P., \& Roberts, M. S. (1994). Skin permeability and local tissue concentrations of NSAIDs after topical application. Journal of Pharmacology and Experimental Therapeutics, 268, 144-151.

Slayter, M. A., Hensley, M. J., \& Lopert, R. (1997). A randomized controlled trial of piroxicam in the management of acute ankle sprain in austrailian regular army recruits: The kapooka ankle sprain study. American Journal of Sports Medicine, $25,544-553$. 
Soltow, Q. A., Betters, J. L., Sellman, J. E., Lira, V. A., Long, J. H. D., \& Criswell, D. S. (2006). Ibuprofen inhibits skeletal muscle hypertrophy in rats. Medicine \& Science in Sports \& Exercise, 38, 840-846.

Stone, M. B., Merrick, M. A., Ingersoll, C. D., \& Edwards, J. E. (2002). Preliminary comparison of bromelain and ibuprofen for delayed onset muscle soreness management. Clinical Journal of Sport Medicine, 12(6), 373-378.

Taioli, E. (2007). Use of permitted drugs in Italian professional soccer players. British Journal of Sports Medicine, 41(7), 439-441.

Thorsson, O., Rantanen, J., Hurme, T., \& Kalimo, H. (1998). Effects of nonsteroidal antiinflammatory medication on satellite cell proliferation during muscle regeneration. American Journal of Sports Medicine, 26(2), 172-176.

Thuyne, W. V., \& Delbeke, F. T. (2008). Declared use of medication in sports. Clinical Journal of Sports Medicine, 18(2), 143-147.

Tokmakidis, S. P., Kokkinidis, E. A., Smilios, I., \& Douda, H. (2003). The effects of ibuprofen on delayed muscle soreness and muscular performance after eccentric exercise. Journal of Strength \& Conditioning Research, 17(1), 53-59.

Trappe, T. A., Fluckey, J. D., White, F., Lambert, C. P., \& Evans, W. J. (2001). Skeletal muscle PGF(2)(alpha) and PGE(2) in response to eccentric resistance exercise: Influence of ibuprofen acetaminophen. Journal of Clinical Endocrinology and Metabolism, 86(10), 5067-5070.

Trappe, T. A., White, F., Lambert, C. P., Cesar, D., Hellerstein, M., \& Evan. W. J. (2002). Effects of ibuprofen and acetaminophen on postexercise muscle protein 
synthesis. American Journal of Physiology - Endocrinology and Metabolism, 282, E551-E556.

Trappe, T. A., Carroll, C. C., Dickinson, J. M., LeMoine, J. K., Haus, J. M., Sullivan, B. E.,...Hollon, C. J. (2011). Influence of acetaminophen and ibuprofen on skeletal muscle adaptations to resistance exercise in older adults. America Journal of Physiology - Regulatory, Integrative and Comparative Physiology, 300(3), R655R662.

Trelle, S., Reichenbach, S., Wandel, S., Hildebrand, P., Tschannen, B., Villiger, P.,...Juni, P. (2011). Cardiovascular safety of non-steroidal anti-inflammatory drugs: Network meta-analysis. British Medical Journal, 342, c7086.

Tscholl, P., Junge, A., \& Dvorak, J. (2008). The use of medication and nutritional supplements during FIFA World Cups 2002 and 2006. British Journal of Sports Medicine, 42, 725-730.

Tscholl, P., Alonso, J. M., Dolle, G., Junge, A., \& Dvorak, J. (2010). The use of drugs and nutritional supplements in top-level track and field athletes. American Journal of Sports Medicine, 38(1), 133-140.

Van Wijck, K., Lenaerts, K., Van Bijnen, A. A., Boonen, B., Van Loon, L. J. C., Dejong, C. H., \& Buurman, W. A. (2012). Aggravation of exercise-induced intestinal injury by ibuprofen in athletes. Medicine \& Science in Sports \& Exercise, 44(12), $2257-2262$.

Vane, J. R. (1971). Inhibition of prostaglandin synthesis as a mechanism of action for aspirin-like drugs. Nature New Biology, 231(25), 232. 
Vane, J. R., \& Botting, R. M. (1998). Anti-inflammatory drugs and their mechanism of action. Inflammation Research, 47, S78-S87.

Virchenko, O., Skoglund, B., \& Aspenberg, P. (2004). Parecoxib impairs early tendon repair but improves later remodeling. American Journal of Sports Medicine, 32, $1743-1747$.

Vuolteenaho, I. K., Moilanen, T., \& Moilanen, E. (2007). Non-steroidal antiinflammatory drugs, cyclooxygenase-2 and the bone healing process. Basic \& Clinical Pharmacology \& Toxicology, 102(1), 10-14.

Walker, R. J., Fawcett, J. P., Flannery, E. M., \& Gerrard, D. F. (1994). Indomethacin potentiates exercise-induced reduction in renal hemodynamics in athletes. Medicine \& Science in Sports \& Exercise, 26, 1302-1306.

Wallace, J. L. (1997). Nonsteroidal anti-inflammatory drugs and gastroenteropathy: The second hundred years. Gastroenterology, 112(3), 1000-1016.

Warden, S. J. (2005). Cyclo-oxygenase-2 inhibitors: Beneficial or detrimental for athletes with acute musculoskeletal injuries? Sports Medicine, 35(4), 271-283.

Warden, S. J. (2009). Prophylactic misuse and recommended use of non-steroidal antiinflammatory drugs by athletes. British Journal of Sports Medicine, 43(8), 548549.

Warden, S. J. (2010). Prophylactic use of NSAIDs by athletes: A risk/benefit assessment. The Physician and Sportsmedicine, 38(1), 132-138.

Warner, D. C., Schnepf, G., Barrett, M. S., Dian, D., \& Swigonski, N. L. (2002). Prevalence, attitudes, and behaviors related to the use of nonsteroidal anti- 
inflammatory drugs (NSAIDs) in student athletes. Journal of Adolescent Health, $30,150-153$.

Yamamoto, T., Cohen, A. M., Kakar, N. R., Yamamoto, M., Johnson, P. E., Cho, Y. K., \& Bing, R. J. (1999). Production of prostanoids and nitric oxide by infarcted heart in situ and the effect of aspirin. Biochemical and Biophysical Research Communications, 257(2), 488-493.

Zhang, X., Schwarz, E. M., Young, D. A., Puzas, J. E., Rosier, R. N., \& O’Keefe, R. J. (2002). Cyclooxygenase-2 regulates mesenchymal cell differentiation into osteoblast lineage and is critically involved in bone repairs. Journal of Clinical Investigation, $109(11), 1405-1415$.

Ziltener, J. L., Leal, S., \& Fournier, P. E. (2010). Non-steroidal anti-inflammatory drugs for athletes: An update. Annals of Physical and Rehabilitation Medicine, 53, 278288. 
Appendix A. Survey Instrument

\section{NSAID Use in Collegiate Athletes}

Dear Participant,

Thank you for your willingness to partake in this research study. Please read questions carefully as some of them ask you to provide more than one answer. Also, when answering questions, please notice that some answer options have carried over to another page. Again, the information you provide is completely confidential and will not be used outside of this study, so please answer questions as accurately and honestly as possible. When finished with the survey please turn it in to the envelope at the front of the room. If you have any questions please feel free to ask at any time.

Thank you,

Brian Davis, ATC

\section{Demographic Information}
Age: yrs

Gender (Circle one): Male / Female 


\section{Year of Eligibility in Sport (Circle one): Freshman /}

Sophomore / Junior / Senior

Primary Sport (Circle one): Football / Basketball / Tennis / Cross Country and Track \& Field / Softball / Volleyball / Golf / Soccer

\section{Questionnaire}

\section{History of Use}

1) Have you taken any NSAIDs in your lifetime? (Check all that apply. If you have never taken any NSAIDs, please turn in your survey)

\section{Drug Name/Category Brand Name} Ibuprofen

_ Naproxen

__ Addaprin
__ Advil
_ Motrin

- Naproxen

__ Aleve
__ Naprosyn
_ Anaprox
_ Naprelan

Acetylsalicylic Acid Aspirin 
__ Coxib

__ Celebrex

Vioxx

*Combination*

__ Pain-Off

__ Back Pain-Off

__ Excedrin

__ Midol

Other:

I have never used NSAIDs (Please turn in your survey)

2) When did you first use NSAIDs? (Check one)

_ Pre-School

_ Elementary School

__ Middle School/Junior High School

_ High School

_ College

3) Why did you start taking NSAIDs? (Check all that apply)

_ Influence from parents or other family members Influence from friends, teammates, or coaches Instructed by a doctor or healthcare professional Media influence (commercials, television, internet, etc.) Other reasons: 
4) How often have you taken NSAIDs since you first started using them?

_ Frequently (3-7 days per week)
_ Regularly/Occasionally (1-2 days per week)
_ Infrequently/Irregularly (Once or twice per month)
_ Rarely (Only a few times per year)
_ Never

\section{Sport-Related Use}

5) Are you currently (within the past week) taking any NSAIDs for reasons related to your sport (i.e., injury, soreness, prevention, recovery, etc.)?

$$
\begin{aligned}
& \text { Yes } \\
& - \text { No }
\end{aligned}
$$

6) Are you currently (within the past week) taking NSAIDs that were prescribed to you by a doctor or medical professional (physical therapist, athletic trainer, etc.) for sports-related reasons?

$$
\begin{aligned}
& \text { Yes } \\
& - \text { No }
\end{aligned}
$$

7) Are you currently competing IN-SEASON with your sport? (This includes nontraditional seasons such as fall softball, spring football, summer basketball, etc.)

Yes
- No


8) How often do you use NSAIDs while competing IN-SEASON? (Check one)

_ Frequently (3-7 days per week)

_ Regularly/Occasionally (1-2 days per week)

_ Infrequently/Irregularly (1-3 times per month)

_ Never

9) How often do you use NSAIDs while training in the OFF-SEASON? (Check one)

_ Frequently (3-7 days per week)

_ Regularly/Occasionally (1-2 days per week)

_ Infrequently/Irregularly (Once or twice per month)

_ Rarely (Only a few times per year)

— Never

\section{Behaviors}

10) What are your reasons for using NSAIDs while competing IN-SEASON?

\section{(Check all that apply)}

I do not use NSAIDs during the season

_ Pain relief from injury

__ Preventing injury or pain

_ General soreness

_ Recovery

_ Muscle tightness

__ Increased energy

_ Less cramping Other: 
11) What are your reasons for using NSAIDs while training in the OFF-SEASON? (Check all that apply)

___ I do not use NSAIDs during the off-season

_ Pain relief from injury

_ Preventing injury or pain

_ General soreness

_ Recovery

_ Muscle tightness

_ Increased energy

_ Less cramping

Other:

12) From whom do you PRIMARILY receive your NSAIDs? (Check one)

_ Self-purchased

_ Parents

_ Teammates/Friends

_ Coaches

_ Athletic Trainers

_ Doctors

Other:

13) HOW do you typically determine the dose of NSAIDs to take at a given time when doing sports-related activity? (Check one)

_ Whatever the directions tell me to take

_ Whatever my teammates tell me to take

_ Whatever the athletic training staff tells me to take Whatever my doctor tells me to take 
_ I take doses based on how much pain or soreness I have I take doses based on the amount of activity I will be doing Other reasons:

14) WHAT is the typical dose of NSAIDs you take at a given time for sportsrelated activity? (Check one)

__ 2 pills
4 __ pills
__ 6 or more pills
$200 \mathrm{mg}$
__ $400 \mathrm{mg}$
__ $800 \mathrm{mg}$
__ Higher than $800 \mathrm{mg}$

\section{General Information}

15) Are you aware of any side-effects caused by NSAIDs? (If you answer YES, please list any you know of)

$$
\begin{aligned}
& \text { No } \\
& \text { _ Yes (Please list): }
\end{aligned}
$$

16) Have you ever experienced any side-effects during sports-related activity you believed were CAUSED by using NSAIDs? (If you answer YES, please list any you know of)

No Yes (Please list): 
Appendix B. Consent Form

The Portland State University

Consent to Participate in Research

\section{Non-Steroidal Anti-Inflammatory Drug Use in Collegiate Athletes}

(v. 4/2/15)

You are being asked to participate in a research study that is being done by Brian Davis, who is the student researcher, from the School of Community Health of the College of Urban \& Public Affairs at Portland State University. This research study is being conducted to investigate non-steroidal anti-inflammatory drug (NSAID) use in collegiate athletes. NSAIDs are common medications used for pain, inflammation, fever, and injury. Most of these medications are available without a prescription in stores or pharmacies. For these reasons, NSAIDs are frequently used by athletes to treat pain and dysfunction associated with athletic events. Common brand names for these medications include: ibuprofen, Advil, Aleve, Motrin, Addaprin, Midol, Aspirin, Naprosyn, Toradol, Celebrex, and Vioxx.

Those who agree to participate in this study must be of 18 years of age, currently enrolled at Portland State University, and an active player on their team's roster. If you agree to participate in this study you will be asked to fill-out a questionnaire, which asks questions about your use of and knowledge of NSAIDs. Participants will also be asked to provide their age, gender, and sport. The questionnaire will take approximately 5-10 minutes to complete. Once the questionnaire has been completed and submitted, your participation in this study will be completed and no further action will be needed of you.

Participation in this study will provide important data to the local sports medicine community, which may allow for improvements in medication policies that will directly benefit the athletes at Portland State University and other institutions in the area.

While this study is considered to have minimal risk, there is the possibility that participants may experience stress, emotional distress, inconvenience, and/or loss of privacy, if information provided was to be linked to a certain individual. However, measures will be taken to protect the security of all information you provide. Names will not be provided on questionnaires to minimize the potential for breaches in confidentiality. Questionnaires containing any information from participants will be handled only by the research team. Questionnaires will be administered in private and secure environments. All questionnaires will be placed in sealable folders and kept in a locked cabinet in a secure room. Information from questionnaires will be used solely for the purpose of this research study, and no specific information will be provided to coaches, teammates, or administrators. Results of this study will be shared only with the sports medicine staff at PSU in order to evaluate and improve policies on medication use. Information will be reported in aggregate (i.e., no single participant's data will be 
shared). Data will be securely stored for three years, after which all questionnaires and data forms will be shredded and discarded. These measures will be taken to protect the security of all the information you provide, but we cannot guarantee confidentiality of all study data.

Keep in mind that your participation in this study is completely voluntary. You have the right to choose not to participate or to withdraw your participation at any point without penalty.

If you have any questions, concerns or complaints at any time about the research study, please contact Brian Davis at (206) 919-6867 or bdavi2@pdx.edu

If you need to contact someone else associated with this research study, please contact Gary Brodowicz at bqgb@pdx.edu

If you have questions regarding your rights as a research participant, you may call the PSU Office for Research Integrity at (503) 725-2227 or 1(877) 480-4400. The ORI is the office that supports the PSU Institutional Review Board (IRB). The IRB is a group of people from PSU and the community who provide independent oversight of safety and ethical issues related to research involving human participants. For more information, you may also access the IRB website at:

https://sites.google.com/a/pdx.edu/research/integrity

\section{CONSENT}

You are making a decision whether to participate in this study. Completion of the questionnaire indicates your consent to participate in this research study.

Thank you for your time

-Brian Davis, ATC 
Appendix C. Human Subjects Approval

Post Office Box 751

Portland, Oregon 97207-0751

503-725-8170 fax

503-725-2227 tel

Human Subjects Research Review Committee: hsrrc@lists.pdx.edu

Date: April 24, 2015

To: Gary Brodowicz / Brian Davis

From: Karen Cellarius, HSRRC Chair

Re: HSRRC approval for your project titled, "Non-Steroidal Anti-Inflammatory Drug Use in Collegiate Athletes" HSRRC Proposal \# 153393

Review Type: Exempt, Category 2

In accordance with your request, the Human Subjects Research Review Committee has reviewed your proposal referenced above for compliance with PSU and DHHS policies and regulations covering the protection of human subjects. The Committee is satisfied that your provisions for protecting the rights and welfare of all subjects participating in the research are adequate, and your project is approved. Please note the following requirements:

Approval: You are approved to conduct this research study after receipt of this approval letter; and the research must be conducted according to the plans and protocol submitted (approved copy enclosed).

Consent: Signed consent is waived from all participants in this study. A written consent statement is required.

Changes to Protocol: Any changes in the proposed study, whether to procedures, survey instruments, consent forms or cover letters, must be outlined and submitted to the Committee immediately. The proposed changes cannot be implemented before they have been reviewed and approved by the Committee.

Adverse Reactions and/or Unanticipated Problems: If any adverse reactions or unanticipated problems occur as a result of this study, you are required to notify the Committee immediately. If the issue is serious, approval may be withdrawn pending an investigation by the Committee. 
Completion of Study: Please notify the Committee as soon as your research has been completed. Study records, including protocols and signed consent forms for each participant, must be kept by the investigator in a secure location for three years following completion of the study (or per any requirements specified by the project's funding agency).

If you have questions or concerns, please contact the Office of Research Integrity in the PSU RSP at 503-725-2227, 1600 SW 4th Ave., Market Center Building, Suite 620. 
Appendix D. Table 2. Survey Response Data

Table 2. Survey Response Data

\begin{tabular}{|c|c|c|c|c|c|c|}
\hline Question & Total (n) & $(\%)$ & Male (n) & $(\%)$ & Female (n) & $(\%)$ \\
\hline Used NSAIDs & 79 & $100 \%$ & 54 & $100 \%$ & 25 & $100 \%$ \\
\hline Not Used NSAIDs & 0 & $0 \%$ & 0 & $0 \%$ & 0 & $0 \%$ \\
\hline First use: Pre-School & 2 & $3 \%$ & 1 & $2 \%$ & 1 & $4 \%$ \\
\hline First use: Elementary & 30 & $38 \%$ & 20 & $37 \%$ & 10 & $40 \%$ \\
\hline First use: Middle School & 25 & $32 \%$ & 19 & $35 \%$ & 6 & $24 \%$ \\
\hline First use: High School & 17 & $22 \%$ & 13 & $24 \%$ & 4 & $16 \%$ \\
\hline First use: College & 5 & $6 \%$ & 1 & $2 \%$ & 4 & $16 \%$ \\
\hline Why Start: Family & 58 & $73 \%$ & 41 & $76 \%$ & 17 & $68 \%$ \\
\hline Why Start: Peers & 25 & $32 \%$ & 17 & $31 \%$ & 8 & $32 \%$ \\
\hline Why Start: Doctor & 36 & $46 \%$ & 21 & $39 \%$ & 15 & $60 \%$ \\
\hline Why Start: Media & 3 & $4 \%$ & 3 & $6 \%$ & 0 & $0 \%$ \\
\hline Why Start: Other & 5 & $6 \%$ & 4 & $7 \%$ & 1 & $4 \%$ \\
\hline Hx use Frequently & 5 & $6 \%$ & 3 & $6 \%$ & 2 & $8 \%$ \\
\hline Hx use Regularly & 11 & $14 \%$ & 9 & $17 \%$ & 2 & $8 \%$ \\
\hline Hx use Infrequently & 34 & $43 \%$ & 21 & $39 \%$ & 13 & $52 \%$ \\
\hline Hx use Rarely & 28 & $35 \%$ & 21 & $39 \%$ & 7 & $28 \%$ \\
\hline Hx use Never & 1 & $1 \%$ & 0 & $0 \%$ & 1 & $4 \%$ \\
\hline Currently Using YES & 26 & $33 \%$ & 18 & $33 \%$ & 8 & $32 \%$ \\
\hline Currently Using NO & 53 & $67 \%$ & 36 & $67 \%$ & 17 & $68 \%$ \\
\hline Currently Prescribed YES & 9 & $11 \%$ & 5 & $9 \%$ & 4 & $16 \%$ \\
\hline Currently Prescribed NO & 70 & $89 \%$ & 49 & $91 \%$ & 21 & $84 \%$ \\
\hline Sport In-Season YES & 32 & $41 \%$ & 10 & $19 \%$ & 22 & $88 \%$ \\
\hline Sport In-Season NO & 47 & $59 \%$ & 44 & $81 \%$ & 3 & $12 \%$ \\
\hline IS use Frequently & 11 & $14 \%$ & 8 & $15 \%$ & 3 & $12 \%$ \\
\hline IS use Regularly & 29 & $37 \%$ & 20 & $37 \%$ & 9 & $36 \%$ \\
\hline
\end{tabular}




\begin{tabular}{|c|c|c|c|c|c|c|}
\hline IS use Infrequently & 28 & $35 \%$ & 18 & $33 \%$ & 10 & $40 \%$ \\
\hline IS use Never & 11 & $14 \%$ & 8 & $15 \%$ & 3 & $12 \%$ \\
\hline OS use Frequently & 2 & $3 \%$ & 2 & $4 \%$ & 0 & $0 \%$ \\
\hline OS use Regularly & 12 & $15 \%$ & 9 & $17 \%$ & 3 & $12 \%$ \\
\hline OS use Infrequently & 28 & $35 \%$ & 17 & $32 \%$ & 11 & $44 \%$ \\
\hline OS use Rarely & 29 & $37 \%$ & 22 & $41 \%$ & 7 & $28 \%$ \\
\hline OS use Never & 8 & $10 \%$ & 4 & $7 \%$ & 4 & $16 \%$ \\
\hline IS No use & 7 & $9 \%$ & 6 & $11 \%$ & 1 & $4 \%$ \\
\hline Reason: P! Relief Inj. & 59 & $75 \%$ & 41 & $76 \%$ & 18 & $72 \%$ \\
\hline Reason: Prevention & 22 & $28 \%$ & 13 & $24 \%$ & 9 & $36 \%$ \\
\hline Reason: Soreness & 44 & $56 \%$ & 34 & $63 \%$ & 10 & $40 \%$ \\
\hline Reason: Recovery & 25 & $32 \%$ & 20 & $37 \%$ & 5 & $20 \%$ \\
\hline Reason: Tightness & 18 & $23 \%$ & 13 & $24 \%$ & 5 & $20 \%$ \\
\hline Reason: Energy & 5 & $6 \%$ & 4 & $7 \%$ & 1 & $4 \%$ \\
\hline Reason: Cramping & 7 & $9 \%$ & 1 & $2 \%$ & 6 & $24 \%$ \\
\hline Reason: Other & 4 & $5 \%$ & 1 & $2 \%$ & 3 & $12 \%$ \\
\hline OS No use & 13 & $16 \%$ & 11 & $20 \%$ & 2 & $8 \%$ \\
\hline Reason: P! Relief Inj. & 47 & $59 \%$ & 31 & $57 \%$ & 16 & $64 \%$ \\
\hline Reason: Prevention & 14 & $18 \%$ & 9 & $17 \%$ & 5 & $20 \%$ \\
\hline Reason: Soreness & 34 & $43 \%$ & 26 & $48 \%$ & 8 & $32 \%$ \\
\hline Reason: Recovery & 16 & $20 \%$ & 13 & $24 \%$ & 3 & $12 \%$ \\
\hline Reason: Tightness & 14 & $18 \%$ & 9 & $17 \%$ & 5 & $20 \%$ \\
\hline Reason: Energy & 2 & $3 \%$ & 2 & $2 \%$ & 0 & $0 \%$ \\
\hline Reason: Cramping & 3 & $4 \%$ & 0 & $0 \%$ & 3 & $4 \%$ \\
\hline Reason: Other & 6 & $6 \%$ & 3 & $6 \%$ & 3 & $12 \%$ \\
\hline Receive: Self Purchased & 45 & $57 \%$ & 32 & $59 \%$ & 13 & $52 \%$ \\
\hline Receive: Family & 16 & $20 \%$ & 12 & $22 \%$ & 4 & $16 \%$ \\
\hline Receive: Peers & 2 & $3 \%$ & 1 & $2 \%$ & 1 & $4 \%$ \\
\hline
\end{tabular}




\begin{tabular}{|c|c|c|c|c|c|c|}
\hline Receive: Coaches & 0 & $0 \%$ & 0 & $0 \%$ & 0 & $0 \%$ \\
\hline Receive: Athletic Trainer & 13 & $16 \%$ & 8 & $15 \%$ & 5 & $20 \%$ \\
\hline Receive: Doctors & 1 & $1 \%$ & 0 & $0 \%$ & 1 & $4 \%$ \\
\hline Receive: Other & 1 & $1 \%$ & 0 & $0 \%$ & 1 & $4 \%$ \\
\hline Dose: Directions & 33 & $42 \%$ & 22 & $41 \%$ & 11 & $44 \%$ \\
\hline Dose: Peers & 0 & $0 \%$ & 0 & $0 \%$ & 0 & $0 \%$ \\
\hline Dose: Athletic Trainers & 17 & $22 \%$ & 11 & $20 \%$ & 6 & $24 \%$ \\
\hline Dose: Doctors & 3 & $4 \%$ & 2 & $4 \%$ & 1 & $4 \%$ \\
\hline Dose: Based on P! & 22 & $28 \%$ & 15 & $28 \%$ & 7 & $28 \%$ \\
\hline Dose: Activity Level & 0 & $0 \%$ & 0 & $0 \%$ & 0 & $0 \%$ \\
\hline Dose: Other & 4 & $5 \%$ & 4 & $7 \%$ & 0 & $0 \%$ \\
\hline Take: 2 Pills & 47 & $59 \%$ & 27 & $50 \%$ & 20 & $80 \%$ \\
\hline Take: 4 Pills & 18 & $23 \%$ & 16 & $30 \%$ & 2 & $8 \%$ \\
\hline Take: $6+$ Pills & 0 & $0 \%$ & 0 & $0 \%$ & 0 & $0 \%$ \\
\hline Take: $200 \mathrm{mg}$ & 1 & $1 \%$ & 1 & $2 \%$ & 0 & $0 \%$ \\
\hline Take: $400 \mathrm{mg}$ & 4 & $5 \%$ & 2 & $4 \%$ & 2 & $8 \%$ \\
\hline Take: $800 \mathrm{mg}$ & 6 & $8 \%$ & 5 & $9 \%$ & 1 & $4 \%$ \\
\hline Take: $800+\mathrm{mg}$ & 1 & $1 \%$ & 1 & $2 \%$ & 0 & $0 \%$ \\
\hline Aware of SE YES & 15 & $19 \%$ & 9 & $17 \%$ & 6 & $24 \%$ \\
\hline Aware of SE NO & 64 & $81 \%$ & 45 & $83 \%$ & 19 & $76 \%$ \\
\hline Experienced SE YES & 3 & $4 \%$ & 3 & $6 \%$ & 0 & $0 \%$ \\
\hline Experienced SE NO & 76 & $96 \%$ & 51 & $94 \%$ & 25 & $100 \%$ \\
\hline
\end{tabular}

Grey and white contrasting was used to separate questions. Each area of different contrast represents a question (e.g. Aware of SE YES and Aware of SE NO is one question, whereas Experienced SE YES and Experienced SE NO is a different question). Questions totaling more than $100 \%$ were "choose all that apply" format and thus many participants responded with more than one answer. Questions below a total of $100 \%$ were due to participants leaving the question blank. "First use" refers to when participants first started taking NSAIDs, "Why start" refers to why participants started taking NSAIDs, "Reason" refers to the reasons participants take NSAIDs related to their sport, "Receive" refers to where participants mainly receive their NSAIDs, "Dose" refers to how participants typically determine a dose of NSAIDs, "Take" refers to the typical dose of NSAIDs participants take. Hx = History, IS = In-season, OS $=$ Off-season, $\mathrm{SE}=$ Side Effects, $\mathrm{P} !=$ Pain . 